Linköping University Medical Dissertations No. 1739

\title{
Health, Experienced Support and School Performance among Children in Out-of-home care
}

\section{Rikard Tordön}

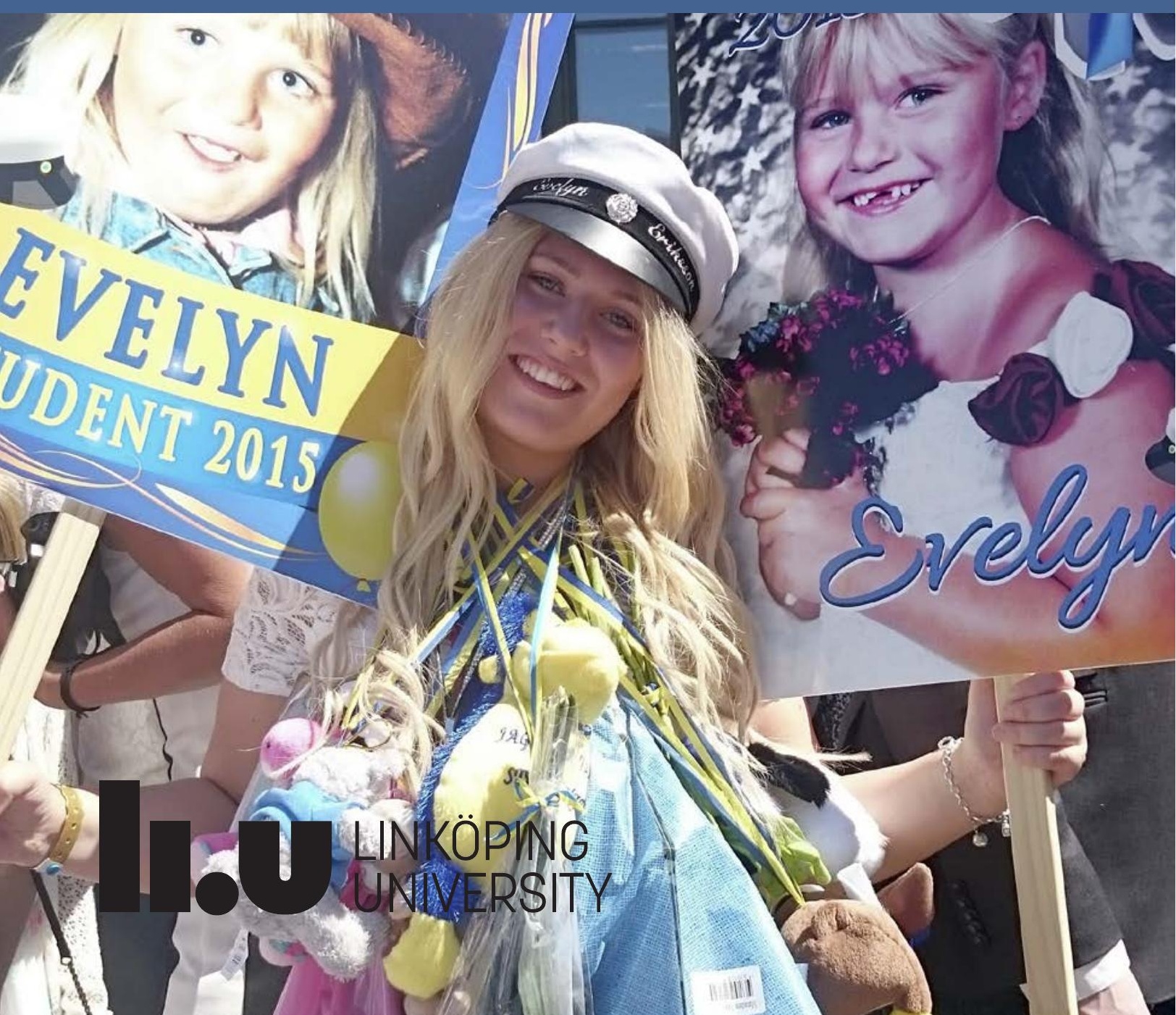




\title{
Health, Experienced Support and School Performance among Children in Out-of-home care
}

\author{
Rikard Tordön
}

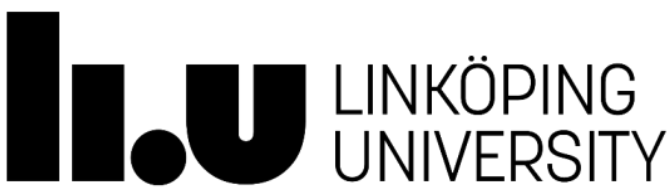

Department of biomedical and clinical sciences

Linköping University

Linköping 2020 
Health, Experienced Support and School Performance among Children in Out-of-home care

(C) Rikard Tordön, 2020

(c) (i) This work is licensed under the Creative Commons license, visit http://creativecommons.org/licenses/by/4.0/.

Printed in Sweden by LiU Tryck, 2020

ISSN: 0345-0082

ISBN: 978-91-7929-859-3 
Children in out-of-home care (OHC) have the same rights as all children, but their path through childhood is paved differently. Some bricks lie askew to stumble on, and some are not there at all. There are more curves and fewer protective barriers. If we truly strive to respect their rights, we must pay specific attention to what happens during their development, not only the long-term outcome. That is the reason why this thesis takes on the "approach to support good development" perspective. The role of the research community is to present knowledge about the developmental path of children. And the role of the stakeholders that manage our society is to pave the developmental path with bricks shaped by that knowledge.

In my understanding, that is how children's rights can be respected. 


\section{Included papers}

1. Tordön, R., Svedin, C.G., Fredlund, C., Jonsson, L., Priebe, G., and Sydsjö, G. (2019). Background, experience of abuse, and mental health among adolescents in out-of-home care: a cross-sectional study of a Swedish high school national sample. Nordic Journal of Psychiatry 73(1), 16-23. doi: 10.1080/08039488.2018.1527397.

2. Tordön, R., Sydsjö, G., Bladh, M., Svanström, J., and Svedin, C.G. (submitted manuscript). Experienced support from family, school and friends among students in out-of-home care in a school-based community survey.

3. Tordön, R., Bladh, M., Svedin, C.G., and Sydsjö, G. (2020). Challenging intellectual, behavioral and educational prerequisites for interventions aimed at school aged children in foster care. A compilation of Swedish test results. Children and Youth Services Review 108, 104598. doi: 10.1016/j.childyouth.2019.104598.

4. Tordön, R., Bladh, M., Sydsjö, G., and Svedin, C.G. (2020). Improved intelligence, literacy and mathematic skills following school-based intervention for children in foster care.

Frontiers in Psychology, doi: 10.3389/fpsyg.2020.00718 


\section{Abstract}

Children in out-of-home care (OHC) have a higher risk for developing poorer health and school achievement, being subjected to more abuse experiences, as well as negative long-term outcomes related to occupational performance, socio-economic status, addiction, and criminality. Research related to children in $\mathrm{OHC}$ is fragmented and the effects of interventions are under-studied.

This thesis aimed to explore health, abuse, support, and preconditions for school among children in $\mathrm{OHC}$ and to assess changes after an intervention targeting foster children's school performance.

Paper I compared pupils in $\mathrm{OHC}$ in last year high school to non-OHC peers in a national survey with 5839 pupils. The study showed that risks of abuse and poor mental health are evident for adolescents in out-of-home care. Also, results indicated a lower disclosure rate of sexual abuse, particularly to police or social services.

Paper II compared pupils in $\mathrm{OHC}$ to peers in birth parent care by analyzing responses in four consecutive year surveys in a regional sample comprising 23798 pupils in $8^{\text {th }}$-year compulsory and $2^{\text {nd }}$-year high school. Responses from the 311 pupils in OHC showed poorer outcomes than did birth-parent care peers in perceived satisfaction with social life and relations, trust to other persons in different relations, abuse experiences online, and sense of security in the school and at home. These results also applied when compared to a subset of pupils living with a single birth parent.

Paper III analyzed prospective test and questionnaire data of intelligence, adaptive behavior, mathematics, literacy skills, and psychosocial wellbeing from 856 children in foster care. Results revealed poorer preconditions for school performance of between 0.5 and 1.0 standard deviations below age-standardized norms. The analysis also provided results regarding different intelligence domains, where working memory showed the lowest scores while perceptual functioning was close to norms. Boys generally scored poorer than girls except in mathematics.

Paper IV explored the effects of a school-based intervention, Skolfam, on a subset of Paper III cohort $(n=475)$. Results showed improved skills in higher-order cognitive executive functions such as reading comprehension, sentence chains, mathematics, and intelligence. For less complex cognitive 
functions, affective functioning or psychosocial symptoms, no improvements were seen, except for reduced hyperactivity.

Conclusion: The studies confirm that children in OHC have poorer mental health, are less satisfied with social life, have more adverse experiences both online and in real life and have poorer preconditions for school performance than do non-OHC peers. Importantly, Skolfam intervention can partially enhance preconditions for school performance. Further studies on longitudinal risk, with a design to identify specific protective factors, development of school-related competencies and ways to support school for children in $\mathrm{OHC}$ are needed. 


\section{Sammanfattning på svenska}

Barn i social heldygnsvård har som grupp högre risker för att utveckla sämre hälsa och skolresultat, vara mer utsatta för övergrepp samt ha sämre långtidsutsikter relaterat till arbetsmarknad, socioekonomisk status, drogberoende och kriminalitet. Forskning om barn i social heldygnsvård är ofta fragmenterad och effekter av olika interventioner är sparsamt utvärderade.

Syftet med avhandlingen var att utforska hälsa, stöd, övergrepp och förutsättningar för skola för barn i social heldygnsvård, samt att bedöma hur förutsättningar för skolprestation förändras genom en intervention som inriktas mot skolresultat för barn i familjehem.

Artikel I jämförde samhällsvårdade studenter i tredje året på gymnasiet med icke samhällsvårdade jämnåriga studenter. 5839 elever besvarade en nationell enkät. Resultatet visade att risker för övergrepp och sämre psykisk hälsa var mer frekvent för ungdomar i samhällsvård. Dessutom var andelen som berättar om övergrepp lägre bland de samhällsvårdade ungdomarna, i synnerhet till polis och socialtjänst.

Artikel II jämförde samhällsvårdade elever med jämnåriga som bor med föräldrar, genom att analysera svaren från fyra på varandra följande års enkäter i ett regionalt urval som omfattade 23798 elever från grundskolans åttonde och gymnasieskolans andra år. Svaren från de 311 eleverna i samhällsvård visade sämre utfall än icke samhällsvårdade i upplevd tillfredsställelse med socialt liv och relationer, tillit till andra personer i olika relationer, erfarenhet av nätövergrepp, samt upplevd säkerhet såväl i skolan som i hemmet, även i jämförelse med en undergrupp av studenter som bor med bara en förälder.

Artikel III analyserade test- och formulärdata av intelligens, adaptivt beteende, matematik, läsfärdigheter och psykosocialt mående av 856 barn i familjehem. Resultaten visade sämre förutsättningar för skolprestation mellan 0.5 och 1.0 standardavvikelser under åldersstandardiserade normer. I analysen från olika domäner av intelligens, visade arbetsminne de lägsta resultaten, medan perceptuell funktion visade sig ligga nära medelvärdet från normeringsstudier. Pojkar hade generellt lägre poäng än flickor, förutom i matematik.

Artikel IV undersökte effekter av en skolbaserad intervention, från ett antal elever från Skolfam kohorten $(n=475)$. Resultaten visade förbättrade 
färdigheter i högre exekutiva funktioner som läsförståelse, meningskedjor, matematik, samt intelligens efter intervention. För mindre komplexa kognitiva funktioner, affektiv funktion eller psykosomatiska symptom noterades inga förändringar, med undantag för lägre hyperaktivitet.

Slutsatserna från dessa studier bekräftar bilden av att barn i samhällsvård har sämre psykisk hälsa, är mindre tillfreds med sitt sociala liv, har mer erfarenheter av övergrepp såväl på nätet som i verkliga livet och har sämre förutsättningar för skolresultat än sina icke samhällsvårdade jämnåriga. Ett viktigt bidrag är att interventionen Skolfam till del kan stärka förutsättningar för bättre skolprestation. Fortsatta studier av longitudinella risker, med möjlighet att identifiera specifika skyddsfaktorer, modeller för att utveckla skolrelaterade kompetenser och sätt att ytterligare stödja barn i samhällsvård behövs. 


\section{Acknowledgements}

This thesis is the result of the commitment and effort of many people, and I would like to express my gratitude to some in specific. My supervisors Gunilla Sydsjö and Carl Göran Svedin, who have paved the path for me, from arranging funds to encouraging support in study designs, proofreading, and moral support when the progress appeared to stall. Marie Bladh and Jennie Svanström, for providing statistical help, guiding me through how they are done and discussing different options. The co-authors to the articles, Cecilia Fredlund, Linda Jonsson, and Gisela Priebe, for stimulating discussions, proofreading, idea brainstorming and valuable feedback along the way. Laura Korhonen, for providing a workgroup environment making me part of a team and for all the assistance in structuring the frame.

My beneficiary and employer Children's Welfare Foundation, for providing the opportunity to spend time learning to practice research while maintaining the connection to my colleagues and your extended network. The colleagues in the Skolfam teams for providing data for the Skolfamstudies. You have together spent thousands of hours compiling test data from archived protocols to spreadsheets possible for me to aggregate. In particular, Emma Tengwall for the efforts in compiling almost a hundred data sets.

I also owe a great thank to all the children and adolescents in OHC, who have provided the data this thesis builds on. You have taken tests and filled questionnaires with your personal experiences that will eventually lead to better support for those who come after you. My colleagues at Barnafrid for making me part of your team, all coffee-time reflections, support, opportunities to take part in events and sharing all the positive spirit that a workgroup can provide.

Last but in many ways most important, my wife and my engine Camilla. You have been there all along, from ordinary grey days when things have proceeded within the expected, to the darkest abyss when manuscripts have been rejected or when the critique has been non-constructive. But you have also shared the joy when boxes are ticked and served the sparkling wine when deserved. Thanks for keeping me reasonably sane by suggesting a walk when work hours are over, and a nudge to focus on work instead of other interesting things, every single day for the last four years. 


\section{Table of Contents}

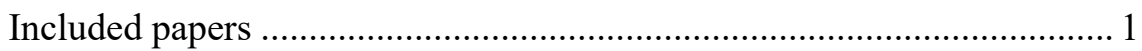

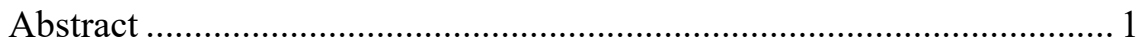

Sammanfattning på svenska .......................................................... 3

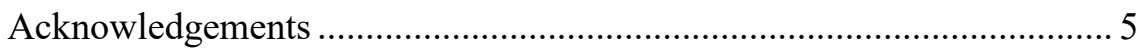

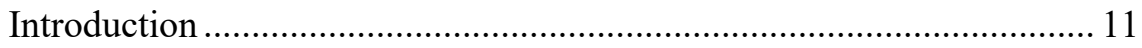

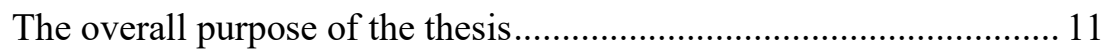

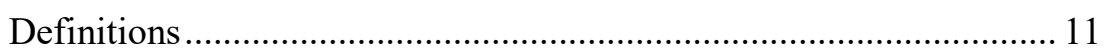

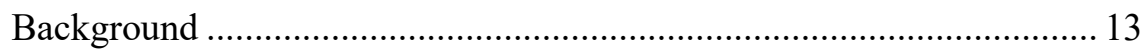

The historical and cultural context of $\mathrm{OHC}$........................................ 13

Societal incentives for developing $\mathrm{OHC}$............................................ 13

Out-of-home care in the literature .................................................... 14

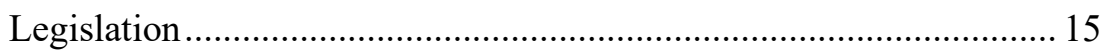

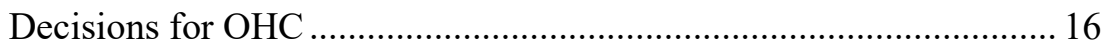

Demographics of OHC in Sweden ..................................................... 17

Previous studies on health, wellbeing, and quality of life in $\mathrm{OHC}$..... 20

School for children in $\mathrm{OHC}$.............................................................. 22

Previous studies on school performance for children in $\mathrm{OHC}$........ 22

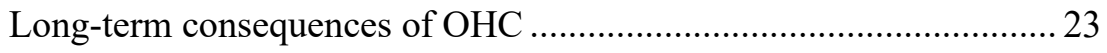

The societal cost of $\mathrm{OHC}$ and long-term exclusion.............................. 23

Prevention of poor long-term outcome for children in $\mathrm{OHC}$............... 25

Interventions promoting resilience processes....................................... 26

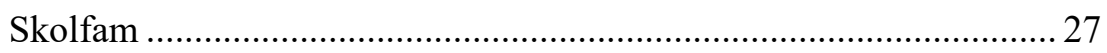

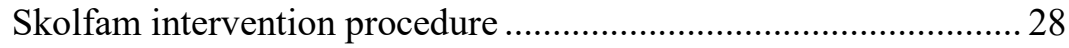

The Skolfam organization ............................................................ 29

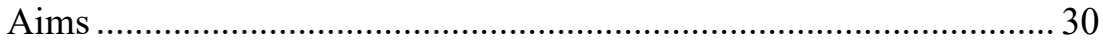

A theoretical framework to the empirical studies.................................. 31

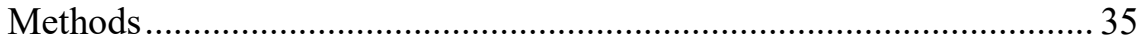

The National survey of 2014, Paper I............................................ 36 
The regional survey “Om Mig”, Paper II ........................................ 36

The Skolfam assessments ............................................................. 37

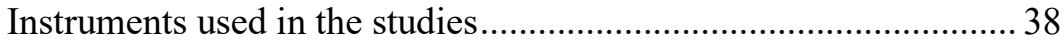

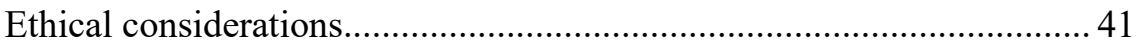

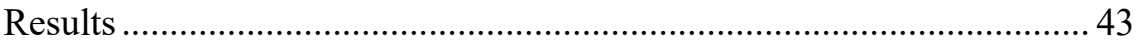

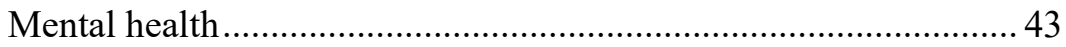

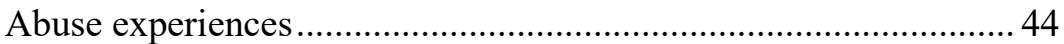

Sexual orientation and non-binary gender...................................... 45

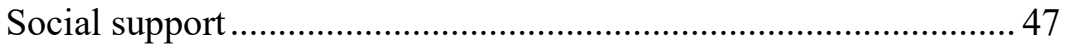

School experiences in Paper II .......................................................... 48

Results from the Skolfam studies ................................................... 49

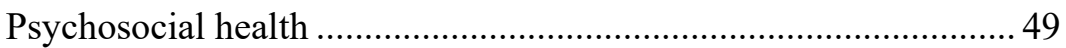

Follow-up tests of psychosocial measures ........................................ 49

Intellectual, literacy and mathematics performance ......................... 51

Follow-up tests of intelligence, literacy and mathematics ............... 52

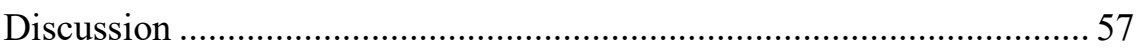

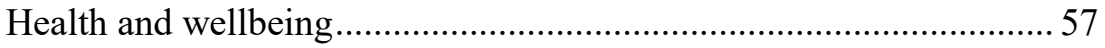

1. More sought mental health care in most categories ..................... 57

2. Higher risks for abuse experiences ............................................. 58

3. Non-binary gender and sexual orientation .................................. 59

4. Less satisfaction with friends, family life and leisure time ..........60 60

5. Poorer trust to non-professional adults, but equal trust to

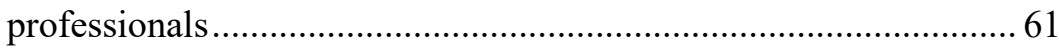

6. Less perceived security in the school and at home...................... 61

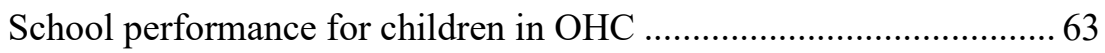

7. Considerably lower mean scores in intelligence, particularly

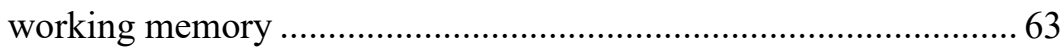

8. Interventions can change conditions for school performance ..... 64

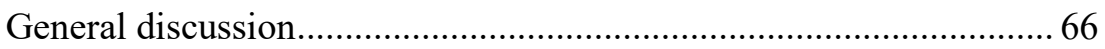

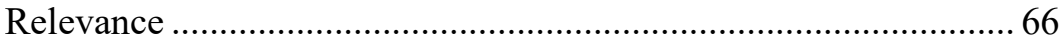




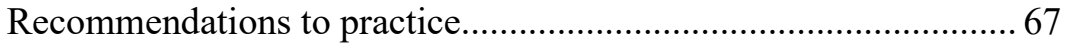

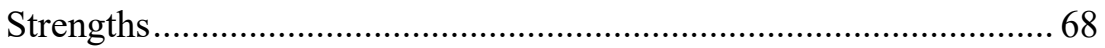

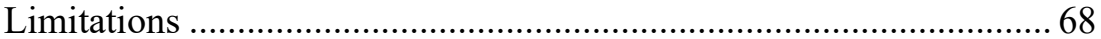

Method considerations for health-, abuse-, and wellbeing aims ..... 69

Method considerations for the studies of school performance........ 70

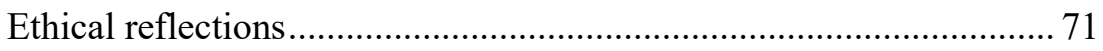

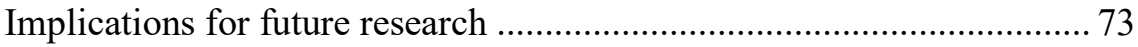

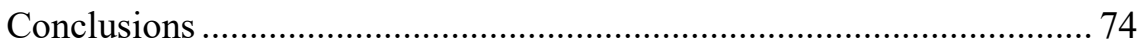

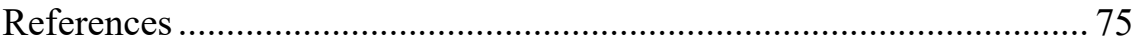




\section{Introduction}

\section{The overall purpose of the thesis}

The purpose of this thesis is to explore developmental aspects for children in OHC. The first two papers focus on the aspects of mental health, abuse experiences, perceived support, and persons to trust in care and school. The third and fourth papers focus on conditions that affects school performance and how these conditions change by an intervention aiming to improve school results.

\section{Definitions}

Child. In this thesis, a child is defined as an individual aged between 0 and 18. When "children and young persons" are used, ages 18 to 20 are included.

Parent. In this thesis to be understood as either the birth parent or parent by adoption.

Legal caregiver. The adult appointed to be legally responsible for a child and to have the authority to take legal decisions on behalf of a child.

Foster parent. An adult appointed by the social welfare board of a municipality to provide the daily care and fostering of a child.

Out-of-home care (OHC). The day- and night care of children out of their parent's home. It includes foster care, residential home care, homes for supported living, and care in state institutions. Out-of-home care does not include boarding school or long-time hospital care. In particularly British literature, Out-of-home care children are often referred to as "Looked after".

Risk. The mathematical probability of a non-desired outcome. It can statistically be presented as Relative Risk (RR), Odds Ratio (OR), or similar terms.

Risk factor. Something that adds to the likelihood of the onset of a nondesired outcome. Either by direct detrimental action, or indirect via an absence of protective actions.

Prevalence. The proportion of a condition within a specific population.

Adversity. A state or instance of serious or continued difficulty or misfortune. 
Adverse Childhood Experiences (ACE). Relates broadly to all adversities that occur during childhood. Normally categorized in three domains: Abuse (physical, emotional, or sexual), Neglect (physical or emotional), and Household Dysfunction (mental illness, incarceration, violence, substance abuse, or divorce).

Home. A place where one expects to reside day and night for a long time. A home should ideally function as a safe haven or base where basic needs are met, such as shelter, heat, food, socialization, and security. For children, it is normally also understood as a place for attachment in close relations and fostering growth and development. One individual can have more than one home. 


\section{Background}

\section{The historical and cultural context of $\mathrm{OHC}$}

Replacing the function of parents is a phenomenon that is recognized in many other mammal species and a history as long as that of mankind (Schino \& Aureli, 2010). It is a basic evolutionary process, where orphan offspring or offspring of parents with inadequate parental capacity, have had to be reared by others to benefit the group in competition with other groups. The group does not gain from excluding children or to leave them with inadequate parents. A child always has the potential to benefit the group in the long run, it dies without care. The better it is reared, the better are the odds of group gains. Throughout history, this has been translated into normative rules, often resolved by ensuring care of those in need. The out-of-home care of children has evolved slightly different in different cultures, but the core value of not leaving a child in need behind is common, as described by Rosenthal (1999) in the following sentences. In cultures where extended families or clans are regarded as important building blocks in society, kinship care in the extended family is preferred (e.g. Middle East, Africa). In cultures with a history of strong governmental or religious institutions, institutional or residential care is more common (e.g. Spain, France, Russia, China). In cultures where core family is the ideal and government influence is less regulated, foster family care with or without kinship is preferred (e.g. US, UK, Scandinavia).

\section{Societal incentives for developing $\mathrm{OHC}$}

The economic and political incentives to increase knowledge and develop more precise interventions to benefit a small proportion of the population in $\mathrm{OHC}$ are not easy to assess for decision-makers in society. From a humanitarian perspective, everybody gains if harm can be reduced and potential benefits of a good upbringing can be enhanced. From a strict political and economic perspective, we still lack evidence on long-term economic gains of investing in preventive health and educational measures for this group, even if the literature give example on economic gains for general health promotion in children (Belli, Bustreo, \& Preker, 2005). The problem from a welfare state perspective of poor long-time outcome is large, and as much as $2 / 3$ of former OHC clients in Norway are by Clausen and Kristofersen (2008, p. 82) estimated to have a troublesome life as adults. Therefore, research aimed to disseminate the societal benefit of investing resources in a group representing a small proportion of the population is needed. 


\section{Out-of-home care in the literature}

In the scientific literature, there is a well-established consensus that children growing up in societal OHC (i.e. daily care provided by other than their parents) have poorer conditions to prepare for life as independent, healthy adults with prospects to pursue their objectives with the same odds as everyone (Kling, Vinnerljung, \& Hjern, 2016; Köhler, Emmelin, Hjern, \& Rosvall, 2015; Vasileva \& Petermann, 2017). There is nothing new in describing yet another area where OHC children fall short to peers reared by parents, but there is a knowledge gap to fill in fine-tuned descriptions of different components in those areas, to advance knowledge concerning links between causes and outcomes.

Intervention research, aiming to guide the development of support for children in OHC is scarce (Forsman \& Vinnerljung, 2012). Literature related to interventions can roughly be summarized by stating that almost all interventions aiming to add to the effect of $\mathrm{OHC}$ itself show promising results, but not broadly for all problematic areas and with limited knowledge of the working mechanisms (Liabo, Gray, \& Mulcahy, 2013). To address the gaps in knowledge concerning what to target in effective intervention programs, further research is needed to disseminate the working mechanisms affecting children with different adverse experiences leading to $\mathrm{OHC}$, and specific deficits caused during care.

Research in $\mathrm{OHC}$ is complex due to the understanding of causality, where adversity can lead to the outcome OHC (Berger, Bruch, Johnson, James, $\&$ Rubin, 2009) as well as OHC itself can be regarded as a factor to an adverse outcome, with adversity before or under $\mathrm{OHC}$ as covariate factors. The underlying ideas to the shortcomings and higher risks of both shortand long-term adverse outcomes for children in OHC differ between research disciplines. In the social sciences, the socio-economic conditions and parental education level are important factors, along with societal organization, resource allocation, and different values guiding the care (Almquist \& Brannstrom, 2014; Haggman-Laitila, Salokekkila, \& Karki, 2019). In the medical sciences, epigenetics, early adverse experiences, trauma or neglect exposure and access to healthcare such as vaccinations, child healthcare visits, and dental care, all serve as important factors (Kungl, Bovenschen, \& Spangler, 2017; Randsalu \& Laurell, 2018). In cognitive and clinical psychology, the discourse focuses on attachment disruptions, neuropsychological development, mentalization, and stressrelated consequences (Jiang, Postovit, Cattaneo, Binder, \& Aitchison, 
2019). In politics, the rights of the child, as expressed in international conventions are in focus, where dilemmas concerning for example parental sovereignty and the child's best interest are discussed (Bessell \& Gal, 2009).

One area that has gained interest in the last decade is the vulnerability associated with sexual minority orientation and non-binary gender. These factors have been reported as corresponding to poorer mental health (Bränström, Hatzenbuehler, Tinghög, \& Pachankis, 2018; Miller \& Grollman, 2015). Children in OHC have, in international research, been identified as a group where these factors are more common than in the general population (Dettlaff, Washburn, Carr, \& Vogel, 2018; B. D. M. Wilson \& Kastanis, 2015), and are therefore of interest to explore further in the Swedish OHC population.

\section{Legislation}

In Swedish legislation, two laws regulate social OHC. The Social Services Act (2001:453) regulates voluntary care with consent from caregivers, and during 2018, 32459 placements of children to OHC were done by this law (National Board of Health and Welfare, 2019b). The compulsory placements without caregivers' consent are done with support from the Care of Young Persons (Special Provisions) Act (1990:52). During 2018, 8249 placements were done supported by compulsory law. According to this law, care can be provided without the caregiver's consent following either $2 \S$ stating environmental conditions threatening the child's health or development, or $3 \S$ stating the child's behavior i.e. criminality, substance abuse or other socially detrimental behaviors.

In 1989, the UN Convention on the Rights of the Child (CRC) was adopted by the world leaders and ratified by Sweden without any exceptions in 1990. From Jan $1^{\text {st }}, 2020$ the convention has legal status in Sweden.

Native adoption of children under 18 is, compared to the UK (Ward \& Smeeton, 2017), rare in Sweden, and only possible with caregivers' consent after a legal court decision. There are few exceptions, mental illness, unknown whereabouts, or other special reasons where the caregiver's consent can be overridden. According to the Children and Parents Code (1949:381), foster parents can be appointed legal caregivers for children if the conditions are in the best interest of the child. The purpose is to enhance stability and continuity in their upbringing and family life. This decision is made by a legal court and only after application 
from the social service board in the municipality. During 2018, 23 foster care children were adopted by their previous foster care parents. In the same year, 369 children were given previous foster parents as their new legal caregivers (National Board of Health and Welfare, 2019b). Unfortunately, there are a substantial number of children where information in registries is incomplete regarding the situation after foster care, addressing the need for improved indicators on the national level.

\section{Decisions for $\mathrm{OHC}$}

In Sweden, the decisions for $\mathrm{OHC}$ are made by the social welfare board of the municipality where the child resides. Compulsory care is decided by a legal court after application from the social welfare board. The decision is prepared by officials in the social service authority following an investigation that is guided by legal rules and a recommended routine from the National Board of Health and Welfare. In cases of urgency, the chairperson of the social welfare board can make an interim decision for compulsory out-of-home placement.

Normally, the process starts when a notice of concern is received by the social services, from other welfare officials, schools, healthcare, police, or from others, for example neighbors, who are concerned. Also, parents or children themselves can contact the social service office for support. Social service officials then, within 14 days from receiving the notice of concern, conduct a preliminary assessment of the case to decide if there is a need to initiate an investigation or not. If an investigation is opened, social service officials have legal rights to request information from sources normally protected by integrity rules, such as healthcare journals and crime registries. Interviews with persons that can inform the investigation, including the child, are performed. These legal rights to aggregate information are valid as long as the investigation is open and has to be conducted within four months.

The investigation report is then presented to caregivers and the child, followed by a recommendation with four possible outcomes:

- No support needed $>$ The contact with social services ends.

- $\quad$ Support needed $>$ Voluntary agreement of supportive measures, where $\mathrm{OHC}$ can be included.

- Support needed but no consent from caregivers or children over 15 $>$ The contact with social service ends. 
- Support needed but no consent from caregivers or children over 15 , there is an obvious risk for health and developmental injury $>$ social services decide if an application for compulsive care to the legal court should be made.

When children are taken into social care, society has taken the responsibility to see to that children are reared by others and must fill that responsibility in loco parentis (in place of parents). In short, the result must be at least as good as if their parents would have done it, otherwise, there are no moral grounds to make such a strong intervention. To assess this responsibility, the Social Services Act (2001:453) states that social services handlers are mandated to have regular follow-ups with children in $\mathrm{OHC}$ and to formally consider if the requisites for care are still valid every $6^{\text {th }}$ month. If legal requisites are no longer valid, the child returns to parental care or voluntary care, with no considerations of any other arguments than those pertaining to requisites for compulsory care. This legal practice is currently under debate.

In Sweden, birth-parent rights are strong (Backe-Hansen, Højer, Sjöblom, \& Storø, 2013; Barnombudsmannen, 2020). The principle of a reunion of children taken into care and their birth parents has guided legislation as well as recommendations for practice. This is the reason why native adoptions are rarely recommended to courts by social services. Instead, in the case of foster care, after three years of continuous care, the foster parents can be appointed as legal caregivers. This is intended to resolve both the issue of practical caregiving with consent to, for example, vaccinations, health care, opening bank accounts and legal agreements where parents normally would consent on behalf of their children, but also provide the child with a better base for long-term stability (Prop. 2002/03:53). Until the foster parents are appointed legal caregivers, children's parents provide consent when needed if care is voluntary. If the child is cared for under compulsory law, the social service handler can provide consent to actions that otherwise would require parental consent.

\section{Demographics of OHC in Sweden}

There are different forms of OHC in Sweden as well as in other countries. According to statistics from the National Board of Health and Welfare (2019b), the most common is foster care, $59.4 \%$. Foster care is carried out by families that accept to provide daily care to a child or a young person. In the social service regulation $3^{\text {rd }}$ chapter $2 \S$, a foster care home is defined 
as "... a private home, assigned by the social service board, receives a child for steady care and fostering...". Residential care, except for the state-run special residential home care, was chosen for $38 \%$ (National Board of Health and Welfare, 2019b). In residential care, children and young persons are provided with living in a group setting and daily care is provided by professional employees. It is defined by the Swedish Association of Local Authorities and Regions (SKR) as “...professionally managed homes in the social service care receiving individuals for care or treatment in combination with accommodation". Residential care often includes treatment and behavioral training. The Swedish National Board of Institutional Care is intended for children with stronger needs of care, i.e. in need of compulsory care with the physical and legal option to locked facilities. During 2018, $3.2 \%$ of all children in OHC were in such special residential youth homes. "Supported living" was introduced in Sweden in 2016. This form of care is intended for young person's $16-20$ years, able to take care of themselves, but in need of somewhere to live, and was in 2018 chosen for $14.1 \%$, of which slightly more than half were unaccompanied refugees. Table 1.

Table 1. Number of children in $\mathrm{OHC}$ at some time or other during 2018, in Sweden

\begin{tabular}{lrrrrr}
\hline & $\begin{array}{r}\text { Foster } \\
\text { Care }\end{array}$ & $\begin{array}{r}\text { Residential } \\
\text { care }\end{array}$ & $\begin{array}{r}\text { Instit. youth } \\
\text { homes }\end{array}$ & $\begin{array}{r}\text { Supported } \\
\text { living }\end{array}$ & $\begin{array}{r}\text { Total } \\
\text { OHC* }\end{array}$ \\
\hline 0-6 years & 3338 & 1111 & 1 & 17 & 4118 \\
7-12 years & 4658 & 758 & 17 & 11 & 5211 \\
13-14 years & 2433 & 635 & 93 & 6 & 2892 \\
15-20 years & 12649 & 12234 & 1123 & 5445 & 26604 \\
\multicolumn{1}{c}{ Boys } & 13796 & 11355 & 818 & 4695 & 26329 \\
$\quad$ Girls & 9282 & 3383 & 416 & 784 & 12496 \\
Total 0-20 & 23078 & 14738 & 1234 & 5479 & 38825 \\
\hline
\end{tabular}

* One person can be registered in different types of care under one year, explaining the difference in sums from the different care forms and the total sum. Source: National Board of Health and Welfare, Statistics on Social Welfare to Children and Young persons 2018.

In Sweden in 2018, there were 38825 children and young persons of up to 20 years of age in $\mathrm{OHC}$ at some time or other, according to public national statistics from the National Board of Health and Welfare (2019b). As a reference, the Swedish population of the same ages was 2490315 persons, which gives an incidence of $1.56 \%$ of the child population being in $\mathrm{OHC}$ at some time during 2018 (Statistics Sweden, 2019a). A comparison to 
Norway (Backe-Hansen et al., 2013) states that for the year 2010, Norway had 61 and Sweden 74 out of 10000 children placed in OHC. According to Pösö, Skivenes, and Hestbæk (2014), Denmark had 104 placed in outof-home care per 10000 on a set day 2010, and Finland 120 per 10000 throughout the year 2007.

Franzén, Vinnerljung, and Hjern (2008) showed marked differences in prevalence for $\mathrm{OHC}$ in a national 15 consecutive year cohort study of all Swedish children born 1981 to 1996, with respect to socioeconomic factors. If the mother was in a cohabiting household in 1997, with higher education, working, and with no subsidies during 1996-98, the prevalence for $\mathrm{OHC}$ was $0.05 \%$ (120 015 children). If the mother was in a single household in 1997, with compulsory school education, unemployed in 1997, and with annual subsidy support $1996-98$, the prevalence was $14 \%$ (8053 children), 250 times higher. The authors conclude that social selection according to socioeconomic conditions, is strong.

In the annual report 2018 from the National Board of Health and Welfare (2019b), there are differences for OHC according to age. Among the youngest, $0-6$ years, roughly $0.5 \%$ are in care, increasing to $0.75 \%$ for children $7-12$ years and $1.25 \%$ in age $13-14$ years. There is a marked increase from 15 years of age, with a share of $3.97 \%$ of children and young person's $15-20$ years in OHC. Regarding distribution between sexes, it is not particularly skewed in the younger ages, with $52-54 \%$ of $\mathrm{OHC}$ children in $0-14$ years age being boys, reflecting the normal population distribution 51.4 to $51.5 \%$ boys in these ages. But in ages $15-17$, boys are in majority with $67.9 \%$ and at ages $18-20$, they represent $79 \%$ of all young persons in $\mathrm{OHC}$.

Unaccompanied asylum-seeking children are a large group within OHC. In total, there were 11554 (29.8\% of all) unaccompanied asylum-seeking children in OHC 2018. Of these, 10147 (87.8 \%) were boys. There is an age gradient in the prevalence, ranging from $0.3 \%$ of the OHC children 0 3 years (children or siblings to other unaccompanied asylum-seeking children) to $40.4 \%$ of the OHC children and young person's age 15-20 (National Board of Health and Welfare, 2019b). During the year 2015, Sweden received 35369 unaccompanied children seeking asylum, around 2/3 were boys from Afghanistan (Statistics Sweden, 2019b). This peak in unaccompanied asylum-seeking children during 2015-16 can explain a substantial part of the high share of unaccompanied asylum-seeking boys in upper adolescence. 


\section{Previous studies on health, wellbeing, and quality of life in $\mathrm{OHC}$}

Following developmental theory, children subjected to societal care of any kind will have a higher risk to develop in a different way than their peers reared by parents. Some factors will possibly influence their socialization, and almost all $\mathrm{OHC}$ children share some of these factors. For example, all are separated from their birth parents and need to assimilate into a new family. Most of them also face a new school or preschool with a new social network of friends. This problem is in part described in a quote from a child in OHC, in Jackson and Cameron (2012, p. 1111):

When changing school you have to start from scratch with friends and everything. That is annoying because you just get adjusted to the classmates and teachers and get used to the books that are used and then you change school and it is all different. New friends, new teachers and new books. Totally different. There are different teaching systems and it is confusing and is bound to influence one's approach to learning.

Changing school is not unusual, and for children in $\mathrm{OHC}$, it might be especially stressful and problematic. If this change is unsupported it might cause strain that triggers a response strategy. Some children prioritize preserving their integrity by limiting investment in new relations to the new family and school friends. Some prioritize the establishment of new relations, quickly learning new family or social network norms and not maintain their old relations to previous friends, relatives or even parents. Regardless of the coping strategy, changes in the social network is always a process that consumes time and energy resulting in a psycho-social resource shortfall (Höjer \& Sjöblom, 2014; Winter, 2012).

In the following paragraphs, some examples of previous research, mostly in the Nordic countries reflecting epidemiologic findings of poorer health for children in $\mathrm{OHC}$ are presented.

In a study where 120 children taken into care in a municipality in southern Sweden were assessed systematically, Kling et al. (2016) found $51 \%$ of the assessed children received at least one referral to further care due to unmet health needs, including prevalent dental decay and overweight problems. In a study of mental health in adolescents in residential youth care in Norway (Jozefiak et al., 2016), 76.2 \% met criteria for at least one DSM-IV diagnosis during the previous three months. A systematic review 
of eight prevalence studies for 3104 children in the child welfare system found a prevalence rate at $49 \%$ for meeting any current mental disorder (Bronsard et al., 2016).

A study of the prevalence of mental disorders in 279 Norwegian foster children aged $6-12$, found that $50.9 \%$ met criteria for one or more DSMIV mental disorders (Lehmann, Havik, Havik, \& Heiervang, 2013). Remarkably high prevalence of Reactive Attachment Disorder (RAD), $19.4 \%$, was reported. Background factors were collected from protocols in municipal care history information and DAWBA (Developmental and Well-Being Assessment) interviews. Results also showed a mean of 3.0 adverse childhood experiences before foster care. Violence exposure events were reported from $35.9 \%$, serious neglect was experienced by 86.3 $\%$. Birth parents with substance abuse was found in $55.3 \%$ and parent's mental disorders in $52.3 \%$. A Finnish study of 614 children diagnosed with RAD (not specifically in $\mathrm{OHC}$ ) concluded that there were associations between offspring RAD and psychiatric diagnoses in parents separately and together (Upadhyaya et al., 2019), demonstrating the difficulty in assessing the causality to the adversities among children in OHC.

Since the beginning of the 2010 decade, the Swedish National Board of Health and Welfare have implemented guidelines and a support strategy for systematic health assessments for children taken into OHC. Despite the routines for assessing and monitoring the health of children in $\mathrm{OHC}$, a study by Randsalu and Laurell (2018) found that only 409 of 11413 (6\%) children in OHC were referred for health assessments between 2012 and 2015. Among those assessed, $29 \%$ revealed depression and anxiety issues, $36 \%$ revealed seeking medical care for traumatic injuries, and $39 \%$ reported missed child health appointments.

Educational completion is another area where children in $\mathrm{OHC}$ show poorer outcomes compared to peers. In a national registry study of all children born 1987 in three Nordic countries, Kaariala, Berlin, Lausten, Hiilamoa, and Ristikari (2018) found elevated risks by 24 to 39 percentage points for not have completed secondary education by age 23 for children in care compared to peers never in care.

There is also a connection between school performance and later health or social problems, suggesting non-failure in school to positively impact later health. Using registry data from ten full birth cohorts in Sweden 1972 1981, Berlin, Vinnerljung, and Hjern (2011) found six to eleven-fold 
higher risks for suicide attempts, substance abuse, and criminality among children with a history of long-term OHC compared to majority population peers. When results were adjusted for poor school results from last year in compulsory school, risks were reduced by 38 to $52 \%$.

\section{School for children in $\mathrm{OHC}$}

The Swedish school is based on national law, guidelines, and curriculum regulating the organization and the content of the education. Education from preschool/kindergarten to upper secondary school is a municipal responsibility and mandatory from the preschool class at age 6 to the $9^{\text {th }}$ year of compulsory school. Most pupils (2018: 84.4 \%) are after the ninth year eligible to upper secondary/high school and continue for three more years, either in a professional training program aiming to prepare for employment, or a theoretical program aiming to prepare for higher education on a university.

Children in OHC attend public schools close to their foster- or residential homes. The state-run institutions have integrated schools with teachers and support staff, for example, special education teachers and psychologists, employed by the institution.

\section{Previous studies on school performance for children in OHC}

School results for children in $\mathrm{OHC}$ are generally far worse than for peers in birth parent care. This is not investigated systematically in annual studies by national authorities in Sweden. The most recent results from the National Board of Health and Welfare (2016) "Progress report in individual and family care", states that in the cohorts born $1982-89$, around $60 \%$ of children in OHC achieved eligibility to upper secondary school, and even lower for cohorts born 1990 - 94 and cohorts born 1995 - 97, indicating a falling trend. Boys had generally lower chances of achieving eligibility than girls and among the different care forms, the results were progressively worse for residential care and institutional care.

Previous studies of children in OHC's intelligence, literacy, and numeracy skills in detail are few and often limited to a heavily burdened population of children such as orphans in the Bucharest Early Intervention Project (Almas, Degnan, Nelson, Zeanah, \& Fox, 2016). Or, based on registry data of young men at draft board tests before military service (Goemans, van Geel, van Beem, \& Vedder, 2016; Hegelund, Flensborg-Madsen, Dammeyer, \& Mortensen, 2018; Vinnerljung \& Hjern, 2011). 


\section{Long-term consequences of $\mathrm{OHC}$}

Studies of long-term outcomes in adulthood from childhood in $\mathrm{OHC}$ show a wide range of poorer prospects compared to those not in $\mathrm{OHC}$, even when controlling for socioeconomic factors (Bäckman, Estrada, Nilsson, \& Shannon, 2014; Gauffin, Vinnerljung, Fridell, Hesse, \& Hjern, 2013). For example, in a Swedish registry study of all former child welfare clients born 1972 to 1981, youth delinquency (convicted for crime between 15 and 20 years) was found in $14.8 \%$ of women and $40.2 \%$ among males. Comparable rates in the normal population were $6 \%$ among women and $18 \%$ of men (Bjorkenstam, Bjorkenstam, Ljung, Vinnerljung, \& Tuvblad, 2013). In the same study, suicidal behavior was found related to youth delinquency in the sample, and $\mathrm{OHC}$ was found to be a prominent risk factor for suicidal behavior.

In Social Report 2010 (National Board of Health and Welfare, 2010, table 7:8), the relative risks for long term consequences among children in $\mathrm{OHC}$ were investigated in census cross-tabulations from nine national registries:

- No secondary school after compulsory, RR (Relative Risk) 3.4

- Substance abuse, alcohol, RR 4.8

- $\quad$ Substance abuse, narcotics, RR 6.8

- Severe delinquency after 20 years age, RR 7.5

- $\quad$ Adolescent parent, RR 3.8

- Suicide after compulsory school, RR 6.4

- $\quad$ Suicide attempt after compulsory school, RR 6.2

- Subsidy dependency at age 25, RR 9.7

However, when controlling for low grades (not having lower grades than 1.0 SD below mean) the relative risks for the poorer outcome were reduced by roughly half, indicating that non-failure in school might be a potent protective factor for long-term detrimental outcome for children in $\mathrm{OHC}$ (National Board of Health and Welfare, 2010, table 7:8).

According to a Swedish interview study of 33 children in foster- or residential home care, most children recognized the school as a strong resilience factor as well as serving as an environment of resort for children in chaotic home situations, (Höjer \& Johansson, 2013).

\section{The societal cost of $\mathrm{OHC}$ and long-term exclusion}

The societal excess costs for physical health care for children in $\mathrm{OHC}$ have recently been investigated in Australia and were found to be AUD 3224 
annually for the first 13 years (Neil et al., 2020). In Sweden, no such studies of excess welfare costs for children in $\mathrm{OHC}$ have, to my knowledge, been performed. From a research perspective, such studies would be necessary to calculate the alternative costs of not providing efficient preventive support, screening for early discovery of health or school problems, or the societal benefit from preventing poor long-term outcome after the care. The insurance company Skandia has a foundation, "Idéer för livet", that develops tools to calculate SROI, Social Return On Investment from preventive ventures in cooperation with researchers in Uppsala and Umeå University (Skandia, 2019). But as far as known, no publications yet are presenting long-term excess costs associated with individuals or welfare society specifically for persons in $\mathrm{OHC}$.

On the other hand, there is Swedish research performed by Hultkrantz, Karpaty, and Vimefall (2017) on the education-earnings links for educational achievement. They assessed the societal benefit of reaching achievement threshold of compulsory school to transit to upper secondary school of SEK 1.1 million. Graduation from upper secondary school program was found to be SEK 1.6 million, just to exemplify one of the economic benefits from preventing school failure.

Spending on social care (both open and out-of-home) for children and youth was in the most recent status report from the National Board Health and Welfare SEK 20.6 billion (National Board of Health and Welfare, 2019a, table 3). From that total cost, 6.8 billion was spent on institutional or residential care and 7.5 billion on foster home care. 6.3 billion were spent on open support to children living with birth parents.

National spending on social care to children has been relatively stable in 2013-2017, but foster care spending has increased by SEK 300 - 400 million for each year during that time. Costs for $\mathrm{OHC}$ tend to be viewed in isolation, as in the accounts from the National Board of Health and Welfare. If a group represents a higher probability of poor health, poor school achievements, and other detrimental outcomes as in the bullet list above, the total societal cost related to the group will be far higher. As an outcome from the "Idéer för livet" initiative, the cost for Sweden related to school failure, i.e. not have finished upper secondary school at age 24, was found to be SEK 53 billion for one age cohort (Hök \& Sanandaji, 2017). In an earlier report in the same series, the societal cost for one individual entering adult life in societal exclusion, i.e. no education, poor health, 
substance abuse, was estimated to between SEK 10 and 15 million (Nilsson, 2012).

\section{Prevention of poor long-term outcome for children in $\mathrm{OHC}$}

Prevention is generally defined by the Cambridge dictionary as "the act of stopping something from happening or stopping someone from doing something" (Cambridge Dictionary). The World Health Organization (WHO) has a more specific definition: Disease prevention, understood as specific, population-based, and individual-based interventions for primary and secondary prevention, aiming to minimize the burden of diseases and associated risk factors. It is used together with the term health promotion, defined as the process of empowering people to increase control over their health and its determinants through health literacy efforts and multisectoral action to increase healthy behaviors (World Health Organization).

In the context of $\mathrm{OHC}$, it is normally understood as either stopping the need to place children in $\mathrm{OHC}$, to stop the need for transit between different $\mathrm{OHC}$ facilities (re-placements or to residential care), or to stop a plausible detrimental outcome from developing into a manifest state. In this thesis, the latter two meanings are specifically relevant, since the empirical data is derived from children already in care.

Preventive measures can be theoretically conceptualized into different stages, as described by Arango et al. (2018) applied in mental health. At the base level, there are general interventions geared towards a whole population, regardless of the subgroup- or individual risk factors, to promote wellbeing and target risk factors. The next stage is selective preventive interventions, geared towards subgroups or individuals with a statistically known higher risk for the development of something detrimental. The top level of prevention is defined by the keyword "indicated" in the meaning that there are detectable manifestations of a known chain of conditions, leading to something worth preventing. In some models, as in Arango et al. (2018) the last stage is further divided into primary, secondary, and tertiary indicated interventions, for different actions to stop further progress related to a disease or service intensity.

In the case of children in $\mathrm{OHC}$, there is scientific evidence of higher risks in virtually any area of health, social, or school outcome. From a prevention aspect, $\mathrm{OHC}$ children as a group are either in the selective stage, with known risks but no visible manifestations, or in the indicated stage. 
But they can of course also belong to other groups with higher known risks with over-lapping needs for preventive interventions, for example, children with neuropsychiatric disorders or abuse experiences. From what is known from previous prevalence research of health or school problems, every third to second $\mathrm{OHC}$ child can be sorted into the indicated stage (Berlin et al., 2011; National Board of Health and Welfare, 2018). The overall picture is that children in $\mathrm{OHC}$ to a higher extent than peers not in care needs preventive interventions beyond the general level geared towards the whole population.

Practicing prevention in $\mathrm{OHC}$ should always be an integrated part of all aspects of child welfare and a multi-professional venture. For example, the evidence from the Swedish registry studies of the "born $1972-1981$ cohort" states that there are links between school performance and mental health (Berlin et al., 2011). Probably, there is a two-way correlation between school performance and mental health. For example, low anxiety levels and good sleep most probably affect the school results positively, and good progress in school results most probably affect low anxiety and sleep in a positive direction, (e.g. reduction of anxiety was found to impact school performance by $d=0.40$ ) (Hattie, 2008). It can be understood as a reciprocal process, where the school could be the treatment or preconditions for psychosocial problems, and the psychosocial situation could be the treatment or shape conditions for school performance.

\section{Interventions promoting resilience processes}

In a review of randomized controlled trials of interventions targeting to improve the outcome for foster children, Leve et al. (2012) found eight interventions targeting either mental health, brain and neurobiological development, relations to parents and peers, or placement disruptions. Interventions with measurable effects were:

- Early childhood Attachment and Biobehavioral Catch-up (ABC), (Bernard et al., 2012)

- Multidimensional Treatment Foster Care for Preschoolers (MTFC-P), (Fisher \& Kim, 2007)

- Bucharest Early Intervention Project (BEIP), (Bos et al., 2011)

- Middle childhood Modified Incredible Years (IY), (Oriana Linares, Montalto, Li, \& Oza, 2006)

- Keeping Foster Parents Trained and Supported (KEEP), (Chamberlain et al., 2008) 
- Middle School Success (MSS), (Kim \& Leve, 2011)

- Fostering Individualized Assistance Program (FIAP), (Clark et al., 1994)

- Multidimensional Treatment Foster Care for Adolescents (MTFCA), (Westermark, Hansson, \& Olsson, 2011).

Two of the included studies, BEIP and MTFC-A, showed large effect sizes, in mental health and relations (Bos et al., 2011; Westermark et al., 2011). Five had at least one area with medium effect size, indicating that there are promising steps taken to develop interventions to promote resilience processes in OHC. Nevertheless, the review also concludes that evaluation studies outside the US are rare and research now needs to focus on understanding the pathways to vulnerability and implement effective interventions.

\section{Skolfam}

Skolfam is a working model aiming to improve school performance for compulsory school children in foster care, developed in Helsingborg, Sweden, and evaluated in a pilot project 2005 - 2008 (Tideman, Vinnerljung, Hintze, \& Aldenius Isaksson, 2011). Results were promising and the pilot study was replicated in Norrköping 2008 - 2011 (Tordön, Vinnerljung, \& Axelsson, 2014). Since then, the model has been implemented through Sweden in more than 25 municipalities. Further information can be found at www.skolfam.se 


\section{Skolfam intervention procedure}

Figure 1. The process in the Skolfam work model.

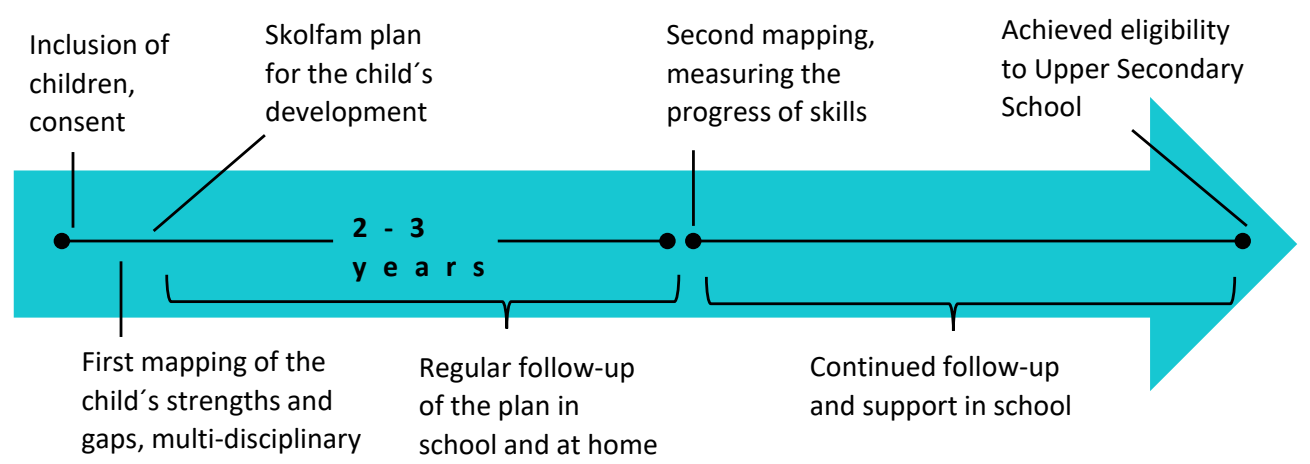

In the Skolfam model, age-standardized tests and questionnaires are used to assess preconditions for school performance in each child. A specific description of instruments included in the model can be found in Methods/Instruments used. The assessments, performed by a psychologist and a special education teacher, include cognitive testing of intelligence, psychosocial status, adaptive behavior, and self-assessment of relational strengths for child and teacher. The assessments also include an interview with the child, teachers, foster parents, and if possible, the parent(-s). The case file from social services, with records of previous foster homes and schools, is reviewed together by the team. In the educational assessment, the special education teacher assesses literacy, reading comprehension, text decoding and spelling, and mathematic strategies and skills.

After the assessments have been performed, the team analyzes preconditions and presents the conclusions for the child, teachers, principal, and foster parents. School staff and foster parents are then encouraged to suggest actions to facilitate good school progress, filling gaps, and planning for optimized challenges considering the results of the assessment. The suggestions are documented in a scheme with objectives and actions that can be evaluated. The development according to the scheme is then monitored in follow-up meetings one to two times every semester, followed by a renewed assessment two to three years after the first assessment. In this assessment, the same age-standardized tests as in the first assessment are used. From the beginning, the second assessment was intended for research evaluation reasons, but it was kept in the model as it served both as a motivation for the children and as a valuable progress 
report to the team. After the second assessment, the monitoring is sustained on a less frequent, but high alert state for the remainder of compulsory school.

\section{The Skolfam organization}

The first municipalities that implemented the model also developed the manual, available at www.skolfam.se/artiklar-och-rapporter-om-skolfam/. With support from the Children's Welfare Foundation, the municipalities also have organized a network to facilitate cooperation in training and consultation to new teams, and to arrange conferences and other activities to assure quality and minimize method washout in the implementation. The organization, national collaboration, and inclusion/exclusion criteria are regulated in a framework document. Today, the Skolfam network is organized in regions and supported by a national coordinator, an online training course and a collaborative online platform to share information in the network. The network is managed by a board of participating Skolfam municipalities and the Children's Welfare Foundation. There is no commercial interest, no fees, and all municipalities finance their work by themselves. The national coordinator is supplied by funding from the Children's Welfare Foundation.

The control documents (manual and organizational framework) states that Skolfam, as a preventive model of school failure, is intended for all children in foster care placed by the municipality organizing the team, in preschool class to compulsory school year 7 at inclusion, regardless of residence within or outside the municipality, and with no other exclusion criteria than a previously known intellectual developmental disorder. However, due to insufficient resource allocation, ques exist, and prioritizations not supported by the control documents occur. 


\section{Aims}

The overall aim of the thesis was to investigate the extent of mental health problems, abuse experiences, perceived support and security in adolescents in OHC. Further, to analyze the intellectual, behavioral, and educational conditions and how conditions develop over time among children in foster care receiving a school-based intervention.

This thesis covers two developmental aspects, health and school performance for children in OHC. These two aspects interact with each other and might influence $\mathrm{OHC}$ children in both short- and long-term perspectives.

Paper I aimed to investigate adverse experiences, mental health, and online sexual abuse among youth in OHC entering adulthood.

Paper II aimed to explore perceived support from family, friends, and school, being deprived of one or both parents, and background factors such as gender, sexual orientation, or being born abroad.

Paper III aimed to describe foster care children's conditions on a functional level close to scholarly performance.

Paper IV aimed to study the dynamic change in preconditions for school performance among foster children. The question that guided design and analysis was: Which preconditions change, and which persist in the first two years of a school-based intervention for foster children? 


\section{A theoretical framework to the empirical studies}

Drawing on the ecological systems theory by Bronfenbrenner (1979), there are different levels of environmental context (systems) in which the development of individuals occurs. For children and youth in $\mathrm{OHC}$, the theory can serve as a framework for understanding the complexity and uniqueness of the preconditions the developmental paths take. In this section, this will be further explained to bridge each part of the theory to putative measures on the specific detrimental impact for children in $\mathrm{OHC}$. Some examples also apply to all children exposed to maltreatment, but not in $\mathrm{OHC}$, others reflect conditions exclusive for $\mathrm{OHC}$ children. Table 2 provides a summary and adds plausible counteractions to the exemplified detrimental impact.

Microsystem: The direct and immediate impact on a child's development from agents with a person-to-person interaction reoccurring regularly. This system includes family members, teachers, neighbors, and peers. For children in $\mathrm{OHC}$, this system is more complex and includes more agents and more interruptions. There are foster parents most often adding to rather than replacing the parents, and a completely new social network related to the new family or residential home. Often, the whole microsystem of relational agents is replaced more than once when children in $\mathrm{OHC}$ are relocated to new places.

The empirical counterparts to Bronfenbrenner's theoretical microsystem are for example trust in relations depending on relational investment, social leisure activities, perceived safety, and social learning of adaptive behavior. Hypothetically, with more interruptions and more complex interactions, empirical measurements of these functions would be affected.

Mesosystem: The interconnections between different microsystems where the child is included. Also, in this system, the conditions for children in $\mathrm{OHC}$ differ from peers not in OHC. There is more than one set of adults with parental functions that interact with these children, and there is a need to transfer information between microsystems that in these cases are regulated by integrity and secrecy laws.

The empirical counterparts to this part of the ecological systems theory are similar to those in the microsystem. In this level, a third agent as the social service handler intervenes in direct contacts in monitoring interviews, 
takes part in school meetings, and sometimes supervises meetings with birthparents. Hypothetically, restraints due to information secrecy and regulated contacts would affect for example depressive and anxiety measures, behaviors interpreted as misconduct, frustration and stress expressed as aggression or hyperactivity.

Exosystem: Links between agents that indirectly relate to the child. Applied in an OHC setting, these are, for example, regulations of care time with birth parents. The parental authority is not evident since there are social service handlers that have the ultimate mandate to decide on important issues. The child's whole microsystem is subject to renewed considerations every sixth month, where the intention expressed in legal and social service practice is a reunion with birth parents.

The empirical counterparts would be an affected long-time sense of belonging, possibly orienting relational needs online since the physical and social real-life world is less stable. Looser relational ties to $\mathrm{OHC}$ microsystems due to repeated transfers could hypothetically lead to indiscrete social contacts online and in real life, raising the risk for abuse or detrimental social relations.

Macrosystem: The culture and values influencing the child's development both directly and via meso- and microsystems. In this system, complex and hard questions arise concerning OHC. Shame and guilt by proxy for one's insufficient parents, the children's or parent's lack of social behavior skills, or how foster parents relate to their double roles as both paid to rear children and altruistic loving parents. The values of strong bonds based on "blood-line" versus "social upbringing" is evident in the macrosystem, influencing legislation and the public debate. In this system, general values of methods, support, and prioritizing welfare for children in groups with higher risks of poor health and school achievement are also influencing the development of children in OHC.

Empirical counterparts to the macrosystem would be poorer self-esteem and lowered expectations of the child's performance in competitive leisure activities or school activities. The effect of overly used or misdirected sympathy from adults could affect the interpretation of inferior skills or knowledge to have an origin "within the child" instead of an effect of disrupted social and cognitive learning. Hypothetically, it would yield lower scores in tests of social competence in assessments and school subjects. The societal values on $\mathrm{OHC}$ children as generally burdened by 
problems could add to social stigma and contribute to lowered self-esteem and performance expectations in empirical measures.

Chronosystem: The "timeline" system of events and transitions that affect development over time. This might be the most important and theoretically most neglected system in the understanding of developmental path for children in OHC. Their transitions are more frequent than others and involve an almost complete change of microsystem. Social services monitoring and support ends when legal care is transferred or if the child return to parents. Out-of-home care children's trauma experiences are often more severe and frequent, and seldom assessed or treated. As noted in a study of Adverse Childhood Experiences (ACE) in foster care children by Turney and Wildeman (2017), the ACE scores were higher for this group than other vulnerable groups (e.g. poverty, single parent), indicating a broader array of adverse events both before and during care over time, contributing to poorer health. And, their school performance is affected by transitions and poorer preconditions with a small gap related to peers the first years and then gradually widening gap along with the childhood and adolescence (Jackson \& Cameron, 2012).

The empirical counterparts to the chronosystem would be any measures that indicate a decreased function, worsened mental health, the aggregated impact of untreated trauma or neglect or a lack of expected progress over time, compared to peers. Hypothetically, the chronosystem's effect could be understood as a factor in the strict mathematical meaning, multiplying the sum of all other developmental conditions with time. If the sum of all contributing developmental factors is less than 1.0, there will be a gradual decrease compared to peers. Whereas if the sum of all developmental factors is over 1.0, the development will increase over time above peerrelated norms. Drawing further on that hypothesis, even a small change, from for example 0.97 to 1.02 would change the developmental direction from negative to positive. 
Table 2. A summary of putative detrimental impact for OHC children, and plausible counteractions, applied upon different developmental systems by Ecological systems theory (Bronfenbrenner, 1979).

\begin{tabular}{|c|c|c|}
\hline $\begin{array}{l}\text { Development } \\
\text { systems }\end{array}$ & $\begin{array}{l}\text { Out-of-Home care } \\
\text { detrimental impact by: }\end{array}$ & Plausible counteractions: \\
\hline Microsystem & $\begin{array}{l}\text { An extended number of } \\
\text { relations. } \\
\text { Changes of the entire } \\
\text { microsystem causing } \\
\text { challenges for attachment- } \\
\text { and social development, } \\
\text { affect regulation, learning, } \\
\text { and mentalization. }\end{array}$ & $\begin{array}{l}\text { Preventive school assessments to } \\
\text { spot children's gaps and strengths. } \\
\text { Support stable attachment and } \\
\text { development of affective functions. } \\
\text { Promote placement stability when } \\
\text { children benefit. } \\
\text { Social leisure activities. }\end{array}$ \\
\hline Mesosystem & $\begin{array}{l}\text { Dual parental interactions } \\
\text { (children affected by } \\
\text { disputes foster-birth } \\
\text { parents), secrecy and } \\
\text { integrity boundaries } \\
\text { between welfare agents. }\end{array}$ & $\begin{array}{l}\text { Better information flow and support } \\
\text { to co-operation. } \\
\text { Transparency over integrity. }\end{array}$ \\
\hline Exosystem & $\begin{array}{l}\text { Regulations of birth-parent } \\
\text { contacts by social services } \\
\text { and law. } \\
\text { Regular re-assessments of } \\
\text { care based on parent's } \\
\text { rights. }\end{array}$ & $\begin{array}{l}\text { Early transfer of legal caregiver. } \\
\text { Mandated child participation in } \\
\text { decisions. } \\
\text { Re-assessments of care according to } \\
\text { the child's needs. }\end{array}$ \\
\hline Macrosystem & $\begin{array}{l}\text { Shame, concerns, and guilt } \\
\text { by proxy. } \\
\text { Misinterpreted inferior } \\
\text { skills. } \\
\text { The double role of foster } \\
\text { parents. } \\
\text { Bloodline vs. upbringing } \\
\text { parenthood. }\end{array}$ & $\begin{array}{l}\text { Compulsory adoption of infants. } \\
\text { Preventive health assessments and } \\
\text { skills training. } \\
\text { Better training of foster carers and } \\
\text { staff. } \\
\text { Updated parenthood and care } \\
\text { legislation. }\end{array}$ \\
\hline Chronosystem & $\begin{array}{l}\text { Pre-care ACE's not } \\
\text { revealed or treated, or } \\
\text { ongoing during care. } \\
\text { Ongoing long-time impact } \\
\text { Remedy over preventive } \\
\text { actions priority. }\end{array}$ & $\begin{array}{l}\text { Broader long-term management aid } \\
\text { across all welfare functions. } \\
\text { Mandated preventive assessments } \\
\text { of health and school preconditions. } \\
\text { Long-term research designs. }\end{array}$ \\
\hline
\end{tabular}




\section{Methods}

Table 3. Scientific aims, data sources, measures and design for the included studies

\begin{tabular}{|c|c|c|c|}
\hline Aim & Data source & Measures & Design \\
\hline $\begin{array}{l}\text { Investigate adverse } \\
\text { experiences, } \\
\text { mental health, and } \\
\text { sexual abuse } \\
\text { among older } \\
\text { adolescents in } \mathrm{OHC}\end{array}$ & $\begin{array}{l}\text { The national } \\
\text { survey "Young, } \\
\text { Sex and } \\
\text { Internet". } \\
\mathrm{N}=5839 \\
\text { pupils in last } \\
\text { year high } \\
\text { school }\end{array}$ & $\begin{array}{l}116 \text { items related } \\
\text { to background, } \\
\text { risk factors, } \\
\text { abuse, mental } \\
\text { health. TSCC and } \\
\text { RSES. }\end{array}$ & $\begin{array}{l}\text { Cross-sectional } \\
\text { study }\end{array}$ \\
\hline $\begin{array}{l}\text { Explore potentially } \\
\text { preceding } \\
\text { conditions to later } \\
\text { disadvantages } \\
\text { among younger } \\
\text { adolescents in } \mathrm{OHC}\end{array}$ & $\begin{array}{l}\text { The regional } \\
\text { survey “Om } \\
\text { Mig", 2014- } \\
2017 . \\
\mathrm{N}=13200 \\
\text { compulsory } 8^{\text {th }} \\
\text { year and } \\
10598 \text { in } 2^{\text {nd }} \\
\text { year high } \\
\text { school }\end{array}$ & $\begin{array}{l}50 \text { items related } \\
\text { to satisfaction and } \\
\text { support from } \\
\text { friends, home and } \\
\text { school, bullying, } \\
\text { and adverse } \\
\text { online } \\
\text { experiences. }\end{array}$ & $\begin{array}{l}\text { Cross-sectional } \\
\text { study with } \\
\text { comparison } \\
\text { group }\end{array}$ \\
\hline $\begin{array}{l}\text { Explore cognitive, } \\
\text { psychosocial, } \\
\text { literacy and } \\
\text { mathematical } \\
\text { preconditions on a } \\
\text { level close to } \\
\text { school } \\
\text { performance }\end{array}$ & $\begin{array}{l}\text { Skolfam } \\
\text { assessments } \\
2005-2018 . \\
\mathrm{N}=856 \\
\text { baseline } \\
\text { assessments. }\end{array}$ & $\begin{array}{l}\text { WISC-III to V, } \\
\text { ABAS-II } \\
\text { SDQ, Reading } \\
\text { Chains, DLS, LäSt, } \\
\text { Magne } \\
\text { Mathematics }\end{array}$ & $\begin{array}{l}\text { Compilation of } \\
\text { a national } \\
\text { sample related } \\
\text { to normative } \\
\text { data. Cross- } \\
\text { sectional study. }\end{array}$ \\
\hline $\begin{array}{l}\text { Explore how } \\
\text { preconditions } \\
\text { change or persist } \\
\text { after the first two } \\
\text { years of a school- } \\
\text { based intervention } \\
\text { for OHC children }\end{array}$ & $\begin{array}{l}\text { Skolfam } \\
\text { assessments } \\
2005-2018 . \\
\mathrm{N}=475 \text { pairs } \\
\text { from baseline } \\
\text { and follow-up } \\
\text { assessments. }\end{array}$ & $\begin{array}{l}\text { WISC-IV, ABAS-II } \\
\text { SDQ, Reading } \\
\text { Chains, DLS, LäSt, } \\
\text { Magne } \\
\text { Mathematics }\end{array}$ & $\begin{array}{l}\text { Prospective } \\
\text { cohort study } \\
\text { with pairwise } \\
\text { within-subjects } \\
\text { calculation. }\end{array}$ \\
\hline
\end{tabular}

In the following section, the methods for each data source and study are described. 


\section{The National survey of 2014, Paper I}

As an initiative from the state inquiry regarding the sexual exploitation of children (SOU 2004:71), a national survey on youth's experiences and attitudes in sexuality was conducted in 2004 (C. G. Svedin \& Priebe, 2007). The survey was directed towards pupils in the last year of Swedish upper secondary school, typically at 18 -year age. It was repeated with added items covering the Internet as an arena for sexuality in 2009 (Priebe \& Svedin, 2009, 2012) and again 2014 (Fredlund, Svedin, Priebe, Jonsson, \& Wadsby, 2017; Jonsson, Priebe, Bladh, \& Svedin, 2014). It was aimed at third-year pupils in upper secondary school, and 261 schools with 13900 pupils were stratified to reflect a national population, whereof 171 schools with 9773 pupils agreed. The sample consisted of 5839 pupils (response rate $59.7 \%$ ) and there was a possibility to select those who responded "in out-of-home-care" to the question about the living situation. During 2020, the next survey in this series will be conducted and compiled.

Paper I was based on the empirical material from the 2014 survey, where one of the background items was used as a grouping variable to enable an analysis comparing youth living with their parents, $n=5798$, to those living in OHC, $n=41$. The mean age in the birth-parent group was 18 and in the $\mathrm{OHC}$ group 18.2 years. Gender distribution was $54.6 \%$ girls, 44.6 $\%$ boys, and $0.8 \%$ non-binary in the birth parent care group, versus 51.2 $\%$ girls, $41.5 \%$ boys, and $7.3 \%$ non-binary in the OHC group.

\section{The regional survey “Om Mig”, Paper II}

The region of East Sweden, in cooperation with the county and the 13 municipalities within, covering both rural and urban areas with population 452105 (2017), conducts an annual survey aimed at all pupils in $8^{\text {th }}$-year compulsory school and $2^{\text {nd }}$-year upper secondary school. This survey has been conducted since 2014 with small additions and alternations following feedback from the pupils, to provide participation and increase relevance for the youth themselves. In 2017, the region aggregated responses from four consecutive years resulting in a sample of 13200 respondents from compulsory, and 10598 from upper secondary school, in all 23798 valid individual responses. Response rates were fair at $74 \%$ and $60 \%$ respectively.

Of these, 311 respondents answered the question of living conditions with "In foster or residential care", forming the index group of the study. This group was compared to those who answered, "With one parent" or "With parents". Gender distribution in the OHC group was $40.7 \%$ girls, $56.1 \%$ 
boys and $3.3 \%$ non-binary, and in the birth parent care group $50.8 \%$ girls, $48.1 \%$ boys, and $1.0 \%$ non-binary. Age was not a collected parameter.

\section{The Skolfam assessments}

For the Skolfam studies (paper III and IV), the material was compiled by assessment data from 22 Swedish municipalities. Children in Skolfam are all in foster care with a permanency plan and between preschool years age six, and $9^{\text {th }}$ year in compulsory school, normally age 15 . At the time for data collection, the staff and managers in the participating municipalities were given instructions and a protocol to note data for all children that had been assessed according to the Skolfam manual.

The Skolfam model started with baseline assessments, presented in the list below. Age-standardized total- and index scale values from the tests were noted in a protocol, one for each child, along with background data i.e. school year, date, sex, time in the present foster home, and total time in foster care. All protocols were given a unique code and the conversion key was kept by the team. No personal data that could be used to identify participants were collected.

Two years after the baseline testing and start of the Skolfam intervention, the assessments were repeated, using the same instruments. This data was protocoled for those children that had been assessed twice. All individual files were collected and transferred to an IBM SPSS Statistics database, version 24, for analyses. Data from 856 foster children were assessed at least once, and 475 children had data from a second assessment. Since the sample did not include a control group, effect-sizes using a between-group calculation was not possible but were calculated using a within-subjects calculation, based on means, standard deviations and the correlation coefficient between tests, using the formula

$$
d=\frac{m_{1}-m_{2}}{\sqrt{s_{1}^{2}+s_{2}^{2}-}\left(2 r s_{1} s_{2}\right)}
$$

where $\mathrm{m}=$ means, $\mathrm{s}=$ standard deviation, and $\mathrm{r}=$ correlation coefficient. 


\section{Instruments used in the studies \\ Study \#1:}

- The survey "Young Sex and Internet, in a changing world, 2014" (Fredlund et al., 2017; Jonsson et al., 2014; Carl Göran Svedin, Priebe, Wadsby, Jonsson, \& Fredlund, 2015). 116 questions related to background, risk factors, abuse and disclosure of abuse, and sought mental healthcare. Administered by Statistics Sweden in a stratified selection of schools. 171 schools with 9773 pupils, mean age 18 years, agreed to participate. The response rate was $59.7 \%$.

- TSCC, Trauma Symptoms Checklist for Children (Briere, 1996). A self-report trauma questionnaire with 54 items assessing trauma symptoms in six subscales. Swedish translation validated with Chronbach's alpha of .78 to .83 in the subscales and .94 for the total scale.

- RSES, Rosenberg Self Esteem Scale (Rosenberg, 2015). A self-report questionnaire with ten items and a four-grade Likert scale for assessment of self-esteem. Cronbach's alpha .90.

\section{Study \#2:}

- The survey "About Me, 2014-2017" (County of Östergötland, 2018).

Web-administered survey to pupils in $8^{\text {th }}$ year compulsory and $2^{\text {nd }}-$ year upper secondary school. An average (dynamically changes due to pupil's influence) of 50 questions and around 125 answer positions. Covers the domains background, family and friends, health and lifestyle, tobacco and alcohol, school and leisure, life and future.

\section{Study \#3 and \#4:}

- WISC, Wechsler Intelligence Scale for Children, editions III to V (Wechsler, 1991, 2003). Widely used test since the 1950s administered by the psychologist. Assesses intelligence in different composite scales and full-scale intelligence gradient, IQ. Scale with 100 as mean and a fixed standard deviation of 15 points.

- ABAS-II, Adaptive Behaviour Assessment System, $2^{\text {nd }}$ ed. (Harrison \& Oakland, 2008). A questionnaire answered by teachers and (foster-) parents, administered by the psychologist. 
Assesses adaptive behavior in nine domains, presented in conceptual, social, and practical composites and a general ability composite. Uses the same scale as WISC.

- SDQ, Strengths and Difficulties Questionnaire (Goodman, 1997). A questionnaire with 25 items in four problem scales reflecting difficulties: emotional problems, conduct problems, hyperactivity, and peer relations. One strength scale reflecting prosocial behavior. Scores range 0-10 on each scale and 0-40 in the scale of the total problems.

- Reading Chains, versions I and II (Jacobson, 2001, 2014). Assesses skills in visual decoding of letters, words, and sentences. Administered by the special education teacher. Uses, as most pedagogical tests, the Stanine scale 1-9 where 5 is mean and two steps represents one standard deviation.

- DLS, Diagnosis in Reading and Spelling (Järpsten \& Taube, 2002).

Assesses reading and writing skills broader than visual decoding, including word and text comprehension, spelling, and reading speed. Administered by the special education teacher. Reports result in the Stanine scale.

- LäSt, Reading and Spelling (Elwér, Fridolfsson, Samuelsson, \& Wiklund, 2013). Assesses text decoding of actual words and nonsense words. Presents results as a "Reading index" using a percentile scale. Administered by the special education teacher.

- Olof Magne Mathematics Diagnoses (Engström \& Magne, 2003). Assesses mathematics skills in different areas such as number, units and quantity perception, positions, algebra, and numeracy comprehension. Standardized in three studies 1977, 1986 and 2002 in a municipality with around 2000 compulsory school pupils. Reports result in the Stanine scale. Administered by the special education teacher. 


\section{Ethical considerations}

Almost all research involving humans has the potential of harming if not performed with caution and awareness of the risks, as well as continued unnecessary harm can be the outcome if the research is not performed (Becker-Blease \& Freyd, 2006). When the aims for the research involve individuals belonging to groups that can be regarded as vulnerable, the demands on ethical consideration increase. Research involving children and especially children that are in care needs special attention concerning ethical deliberation and methods used. There is also an ethical aspect to consider for research involving populations that entails design difficulties, where research tends to not be conducted, or where sub-optimal methods are used for convenience reasons, resulting in biased data (Bonevski et al., 2014). For example, using parents, foster parents, teachers or social workers to assess children in questionnaires instead of directing questions and interviews with children themselves.

In research with children and adolescents in $\mathrm{OHC}$, there are gatekeepers such as legal caregivers or social workers with the authority to prevent participation, which results in selection bias (Balen et al., 2006).

Another ethical dilemma is the studied children's influence on the research questions and how they will guide the aims and study design. Adult's ideas of what would be of interest to disseminate in research might be based on preconceptions, where children themselves might have questions of more relevance (Larsson, Staland-Nyman, Svedberg, Nygren, \& Carlsson, 2018). In this matter, there is an example of an exception in Paper II, where the About Me survey is upgraded to a certain extent every year after completion, following suggestions from the respondents.

Asking children to reveal sensitive information, such as abuse experiences, sexuality, or mental problems, can be considered as an ethical dilemma. There is a potential of revoking unpleasant memories or causing discomfort on one hand, and the discomfort of not be given the chance to disclose on the other hand. The former is usually temporary and causes minimal discomfort (Yeater, Miller, Rinehart, \& Nason, 2012), and the latter is usually sustained for a long time (Jeffreys, Leibowitz, Finley, \& Arar, 2010).

In short, the methods applied to collect data for the present studies are secondary analysis of information from surveys and tests performed in 
teacher's and psychologist's assessments. Possible harm could emerge at the time for the primary data collection if questions in the surveys triggered painful thoughts or emotions, or if performing in tests was perceived as discomfort. Harm could also emerge if sensitive information would not preserve the integrity of respondents, revealing their participation or personal information.

The measures taken to address potential harm, was partly not possible to control in the primary data collection, but when handling the data several actions to were performed:

- Personal identifiers, such as names, personal code numbers, or combinations of age and names of schools that could indirectly be used for identification, were not collected. The downside of this measure is limitations for matching individual data with other sources for other analyses, which also should be considered since the benefit of the research should exceed the discomfort induced in good research practice.

- If respondents should experience discomfort during or after contribution, there were routines for contacting support persons.

- Data were kept in a secured file location on the university data storage, only accessible for the research team. Data in the Skolfam studies were transferred from local municipalities by direct physical contact. Mobile media storage, such as memory sticks and computer drives, were erased after assuring that the data were secured in the file storage.

In the present studies, the Helsinki declaration principles (World Medical Association, 2013) were preserved and respected. All studies were described in research protocols that were assessed and approved by the Human Research Ethics Committee, Linköping. Registry numbers 131-31, 2019-01482, and 2018/96-31. 


\section{Results}

\section{Mental health}

Paper I studied mental health and abuse experiences among upper secondary school pupils in $\mathrm{OHC}$, compared to non-OHC peers. The results revealed that sought healthcare for mental problems was higher in the $\mathrm{OHC}$ group in almost all sub-categories such as depression, anxiety, and suicide attempts, eating disorders, attention deficit, substance abuse, and nonsuicidal self-injury. The one exception was autism spectrum disorder. There is a methodological comment to be made according to the absence of observed difference in autism; prevalence in the total sample was under $2 \%$ and only 36 respondents in $\mathrm{OHC}$ answered this item, resulting in less reliability in the statistical calculations. Figure 2.

Figure 2. Shares (\%) of pupils in $\mathrm{OHC}$ and birth parent care that have sought healthcare for mental problems (Paper I).

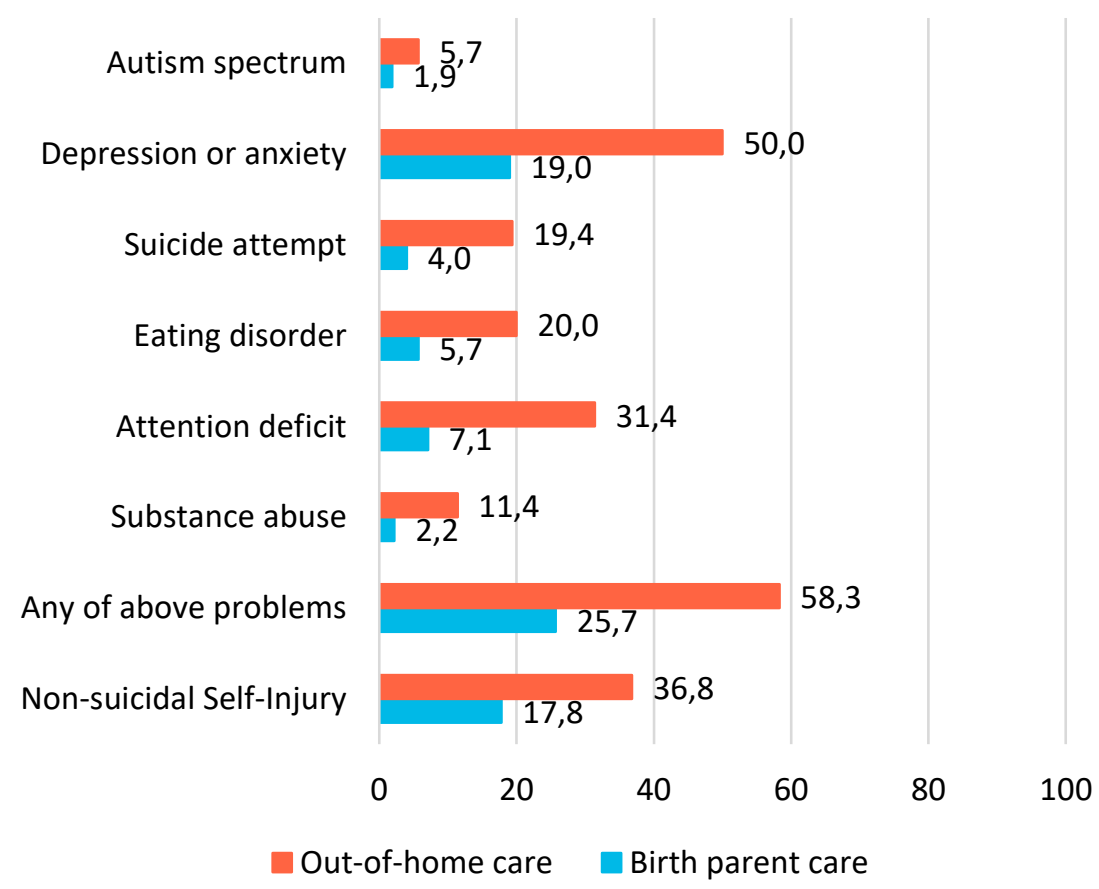




\section{Abuse experiences}

Paper I concluded that the risk for abuse was still evident in a sample containing only those who have succeeded to the last year in upper secondary school. $50.0 \%(n=19)$ of the responding OHC pupils had experienced physical abuse by adults, compared to $31.2 \%(n=1789)$ in the non-OHC group ( $\mathrm{OR}=2.2, p=0.015)$. Sexual abuse, when all different kinds of sexual abuse experiences were included, was not found to differ between groups. However, if only penetrative sexual abuse experiences (oral, vaginal, or anal) were compared, there was a clear difference, $22.0 \%$ in $\mathrm{OHC}$ versus $6.1 \%$ not in care (OR $=4.3, p<.001)$. Psychological abuse experiences were common in both the OHC group $(71.1 \%)$ and the group not in care $(57.7 \%)$ and did not differ significantly in the analysis.

Results in Paper I also showed that pupils in $\mathrm{OHC}$ were less prone to disclose sexual abuse to others, compared to their peers living without OHC. However, we lacked the statistical power to make a general valid conclusion on the disclosure behavior of pupils in OHC. Figure 3.

Figure 3. Shares (\%) of pupils in $\mathrm{OHC}$ and birth parent care that have experienced abuse, and those disclosing sexual abuse (Paper I).

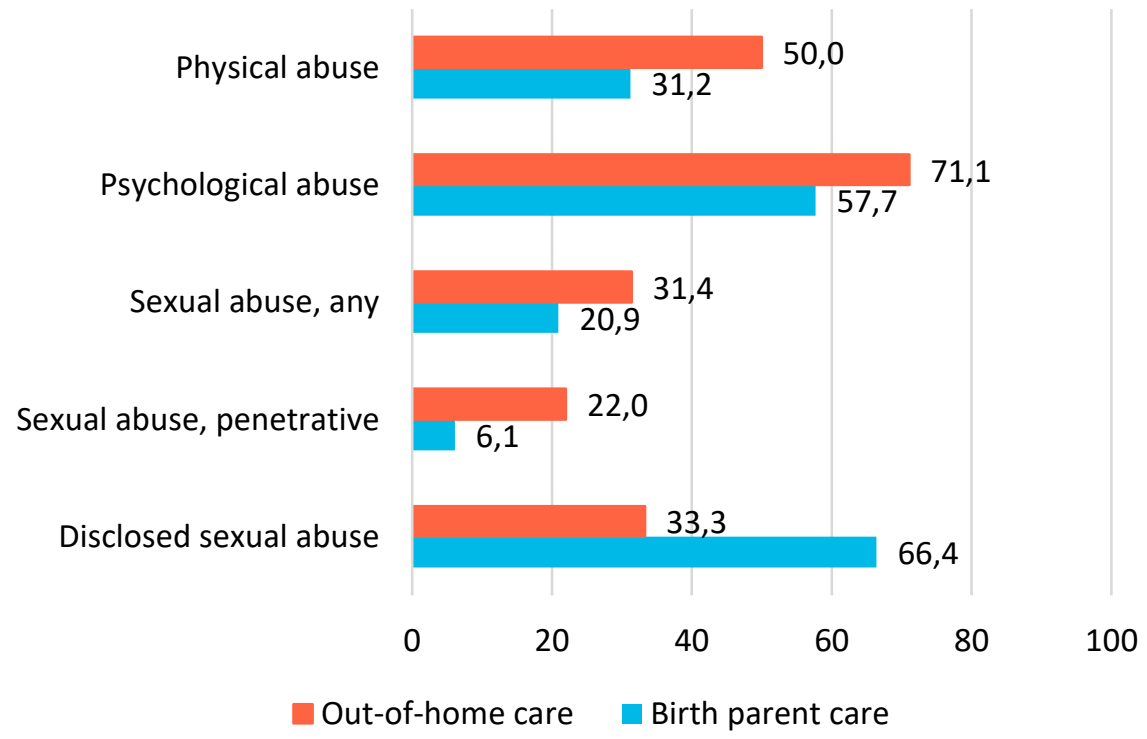




\section{Sexual orientation and non-binary gender}

One finding in the background data regarded sexual orientation. Having a bisexual or uncertain sexual orientation was in Paper I reported by $31.8 \%$ of the pupils in $\mathrm{OHC}$, compared to $11.4 \%$ in the group not in care. Figure 4.

Figure 4. Shares (\%) of sexual orientation among pupils in $\mathrm{OHC}$ and birth parent care (Paper I).

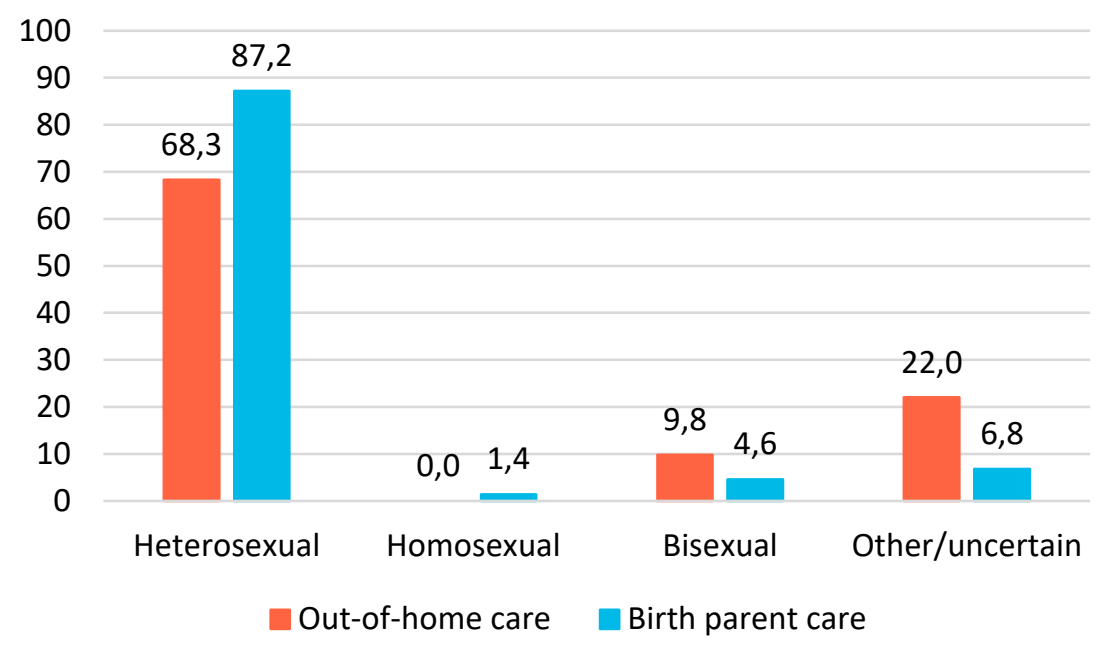


Another statistical anomaly was non-binary gender. In the total material from the national survey in Paper I, $0.9 \%(n=51)$ regarded themselves as belonging to a non-binary gender. Among the pupils in $\mathrm{OHC}$, the share was substantially higher, $7.3 \%(n=3)$. The same tendency, but less marked was found in Paper II, including respondents in $8^{\text {th }}$-year compulsory school, typically 14 years old and $2^{\text {nd }}$-year upper secondary school, typically 17 years old. In this data, $1.0 \%(n=241)$ of the pupils living in birth parent care reported a non-binary gender, versus $3.3 \%(n=10)$ of pupils in OHC. Figure 5.

Figure 5. Shares (\%) of non-binary gender among pupils in OHC and birth parent care Paper I, $n=41$ and Paper II, $n=311$.

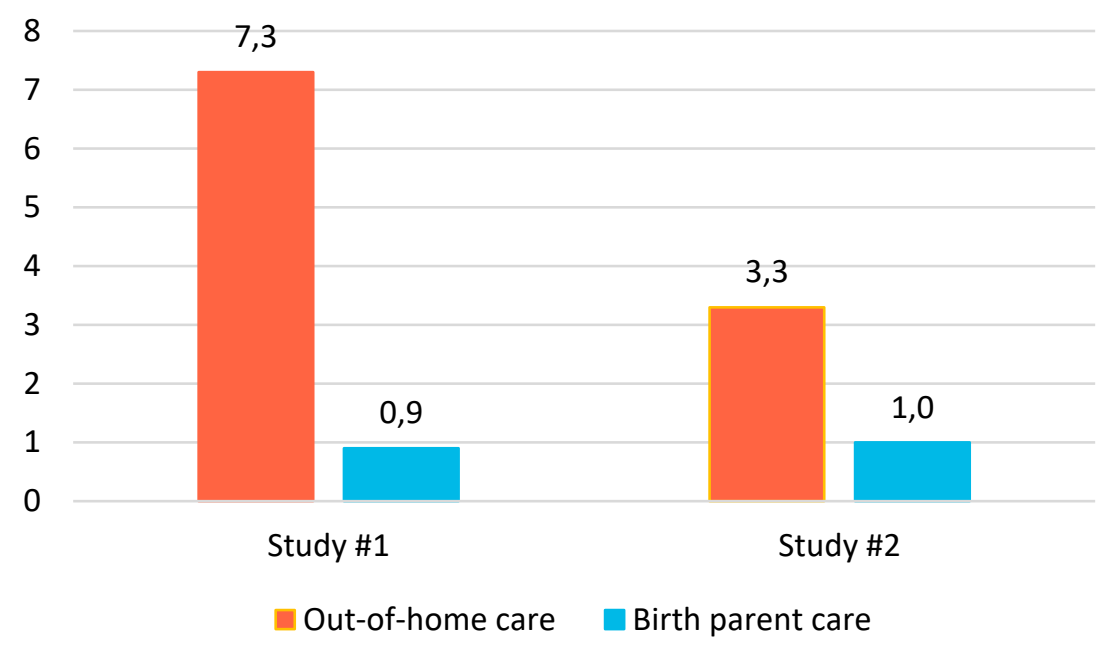




\section{Social support}

In Paper II, results showed that pupils living in $\mathrm{OHC}$ were less satisfied with friends, leisure time, and their families than peers not in OHC. This was the case, at least for leisure time and families even when compared with peers living with only one birth parent. Figure 6 .

Support, expressed as having others to trust when in problems or concerns, did not differ between pupils in OHC and pupils living with birth parents, except for turning to parents, which $21.7 \%$ of the respondents in $\mathrm{OHC}$ stated "would feel hard", compared to $9.5 \%$ of the pupils in parental care and $14.8 \%$ of the pupils in single birth parent care. Regarding trusting professionals, such as teachers, counselors, youth clinics, and school nurses, there was no significant difference. Figure 6.

Having no close friends to trust and tell personal matters to, was reported by $14.1 \%$ of pupils in $\mathrm{OHC}$, compared to $8.1 \%$ of pupils in birth parent care and $10.0 \%$ of pupils in single birth parent care. Also, having experience of being contacted on social media against their will to talk about sex, was recognized by $43.8 \%$ of pupils in OHC, compared to 26.9 $\%$ of pupils in birth parent care. Presented as online abuse once and repeated, respectively, in Figure 6.

In Paper II, $26.2 \%$ of pupils in OHC felt secure in school less than often, compared to $14.5 \%$ among their peers in birth parent care $(p<0.001)$. Feeling secure at home less than often was reported by $21.9 \%$ of pupils in $\mathrm{OHC}$, versus $4.1 \%$ of pupils in birth parent care and $7.7 \%$ among pupils in single birth parent care ( $p<0.001$ in both comparisons). 
Figure 6. Shares (\%) of experienced support and online abuse among pupils in OHC, $n=311$, birth parent care, $n=23487$, and single birth parent care, $n=3$ 003. Paper II.

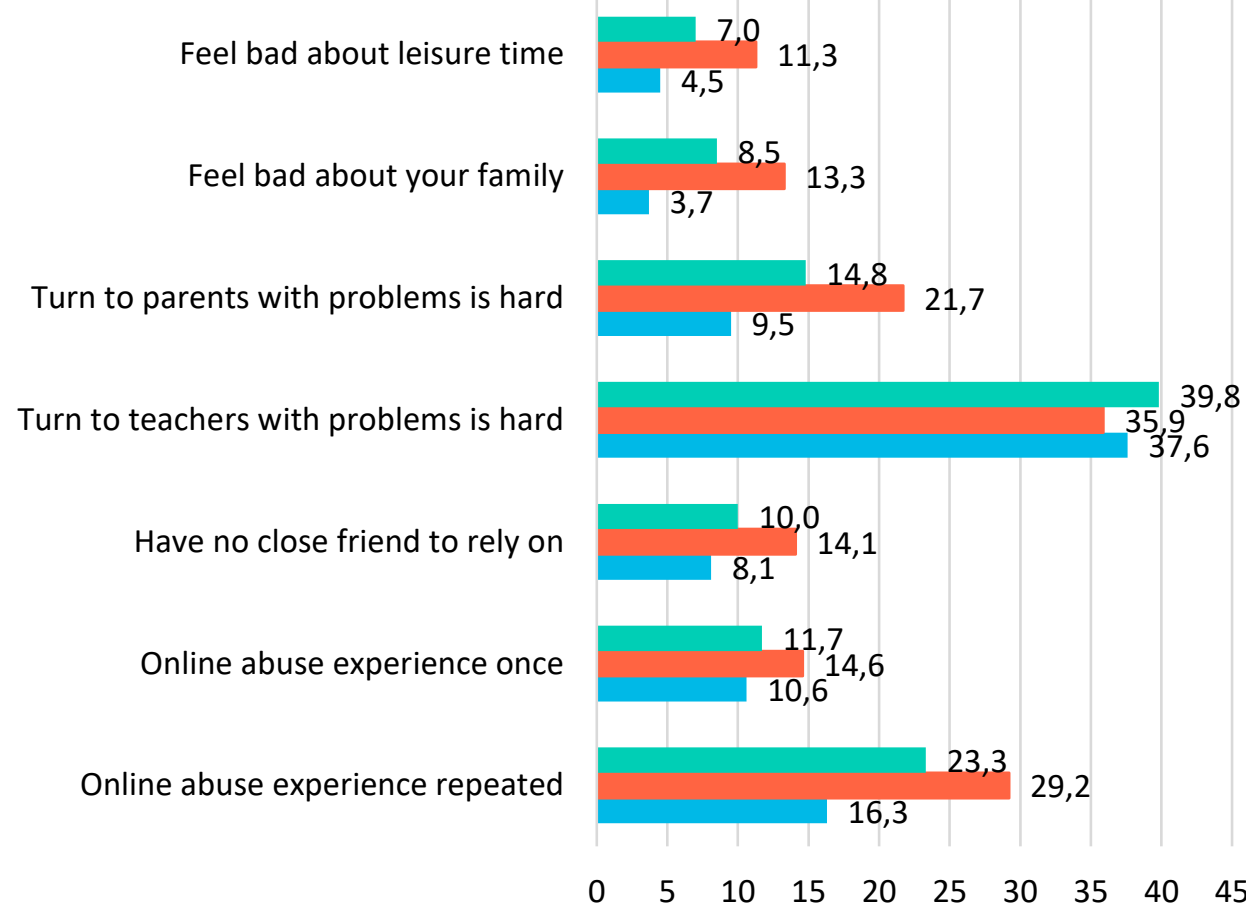

जingle birth parent $\quad$ Out-of-home care $\square$ Birth parent care

\section{School experiences in Paper II}

In Paper II, pupils in OHC reported that they gave up on difficult tasks in school, felt less safe both at school and at home and were bullied, to a higher extent than both peers in birth parent care $(p<0.001)$ and in single birth parent care $(p<0.05)$. 


\section{Results from the Skolfam studies}

Paper III and IV, analyzed preconditions for school performance for children in OHC by compiling data from assessments with tests from 856 children in Skolfam. For 475 children, there were data available from a second assessment, enabling an analysis of the change from pairwise within-subject analyses, two years after the baseline assessment.

\section{Psychosocial health}

The psychosocial health was assessed with a combination of SDQ, Strengths and Difficulties Questionnaire and ABAS-II, Adaptive Behavior Assessment System in $2^{\text {nd }}$ edition. In all problem scales of the SDQ, there were differences to normalization studies reflecting a more burdened situation for children in OHC. The total problem scale mean for the teacher assessments was $11.1(\mathrm{SD}=7.6)$, which should be related to norm mean of $6.6(\mathrm{SD}=6.0)$. Cutoff for the $90^{\text {th }}$ percentile was in the original Swedish normalization study by Smedje, Broman, Hetta, and von Knorring (1999) found to be 14. In the foster parent assessments, the mean for the total problem scale was higher than the teacher's, $13.1(\mathrm{SD}=7.6)$, which should be related to the norm mean for parent assessments $6.1(\mathrm{SD}=4.8)$ and the same cutoff line 14 as in teacher assessments.

In the ingroup comparison, girls had lower scores than boys on problem subscales and higher on the prosocial behavior scale, except for emotional symptoms. The same pattern was found between children with Swedish as the native language and those with Swedish as a non-native language, where the non-native group had lower (better) scores on all subscales, except for emotional symptoms. The hyperactivity subscale stands out on a higher level than the others, in our results as well as in norm studies.

\section{Follow-up tests of psychosocial measures}

Regarding the children's improvement over time (Paper IV), there were declined hyperactivity problems in both teacher's and foster parent's assessments and declined emotional symptoms in foster parent's assessments. Figure 7. 
Figure 7. Means from repeated tests in SDQ problem scores $(n=329-338)$

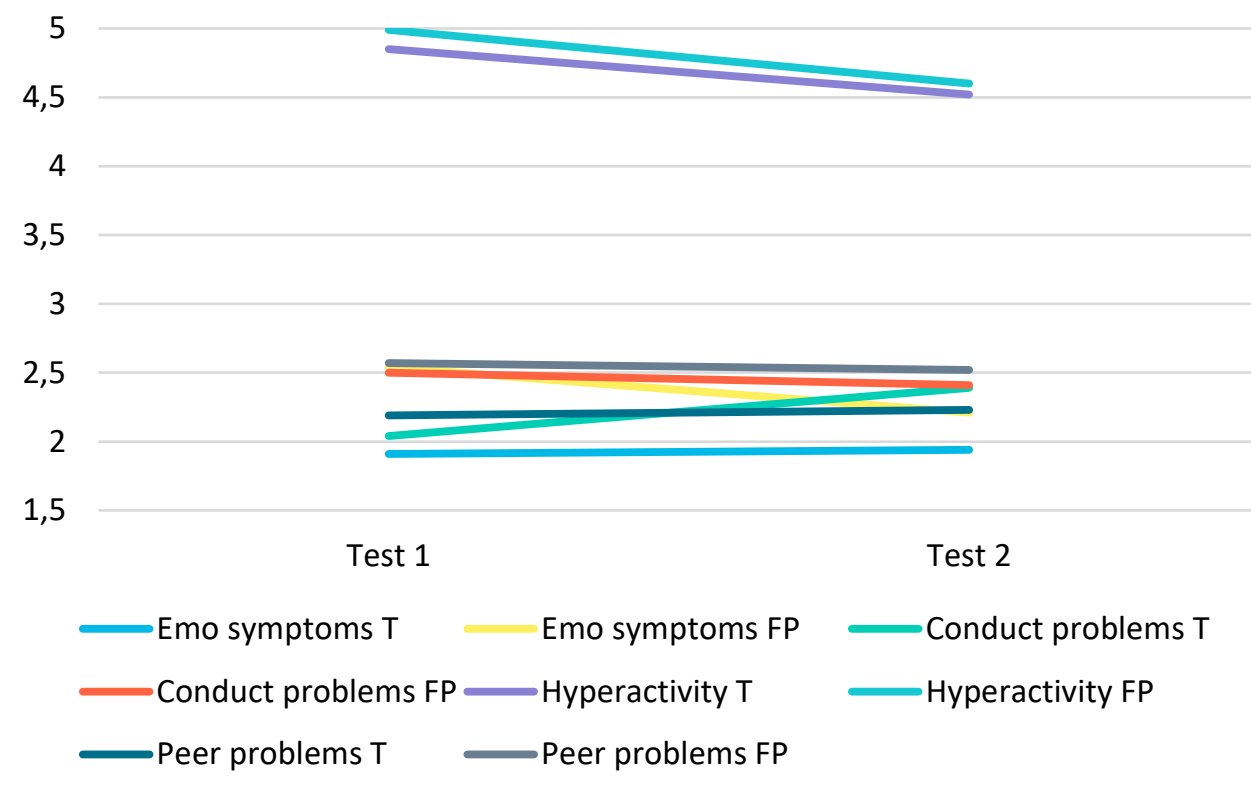

Note: $\mathrm{T}=$ Teacher assessment, $\mathrm{FP}=$ Foster Parent assessment

Adaptive behavior assessments by teachers and foster parents respectively were found to have substantially lower mean scores compared to norms in all composite scales. The general ability composite means from the baseline tests in Paper III were $85.5(\mathrm{SD}=21.2)$ for teacher's and 77.3 (SD $=20.8$ ) for the foster parent's assessments. Girls outscored boys in all subscales $(p<0.001)$ and the means were higher for children with other than Swedish as the native language, albeit with significance only in foster parents' assessments $(p=0.026)$.

None of the means in the subscales of adaptive behavior changed over the two years between the first and second assessments (Paper IV). The ABAS-II general ability means are presented in figure 10, together with the scores from the Intelligence tests since both tests use the same Wechsler scale. 


\section{Intellectual, literacy and mathematics performance}

Children in OHC performed poorer than their peers in birth parent care in normalization studies in intelligence, literacy, and mathematics skills measures. The difference in the total scales was around 0.5 standard deviations below norm means. Results revealed an atypical profile variance in the intelligence tests, where working memory mean was 11.2 points lower than the perceptual reasoning mean that was close to the norm of 100.3 (Paper III). Figure 8.

Figure 8. Means from intelligence test WISC in Paper III. $(n=633-765$. CI $95 \%=+/-0.5)$.

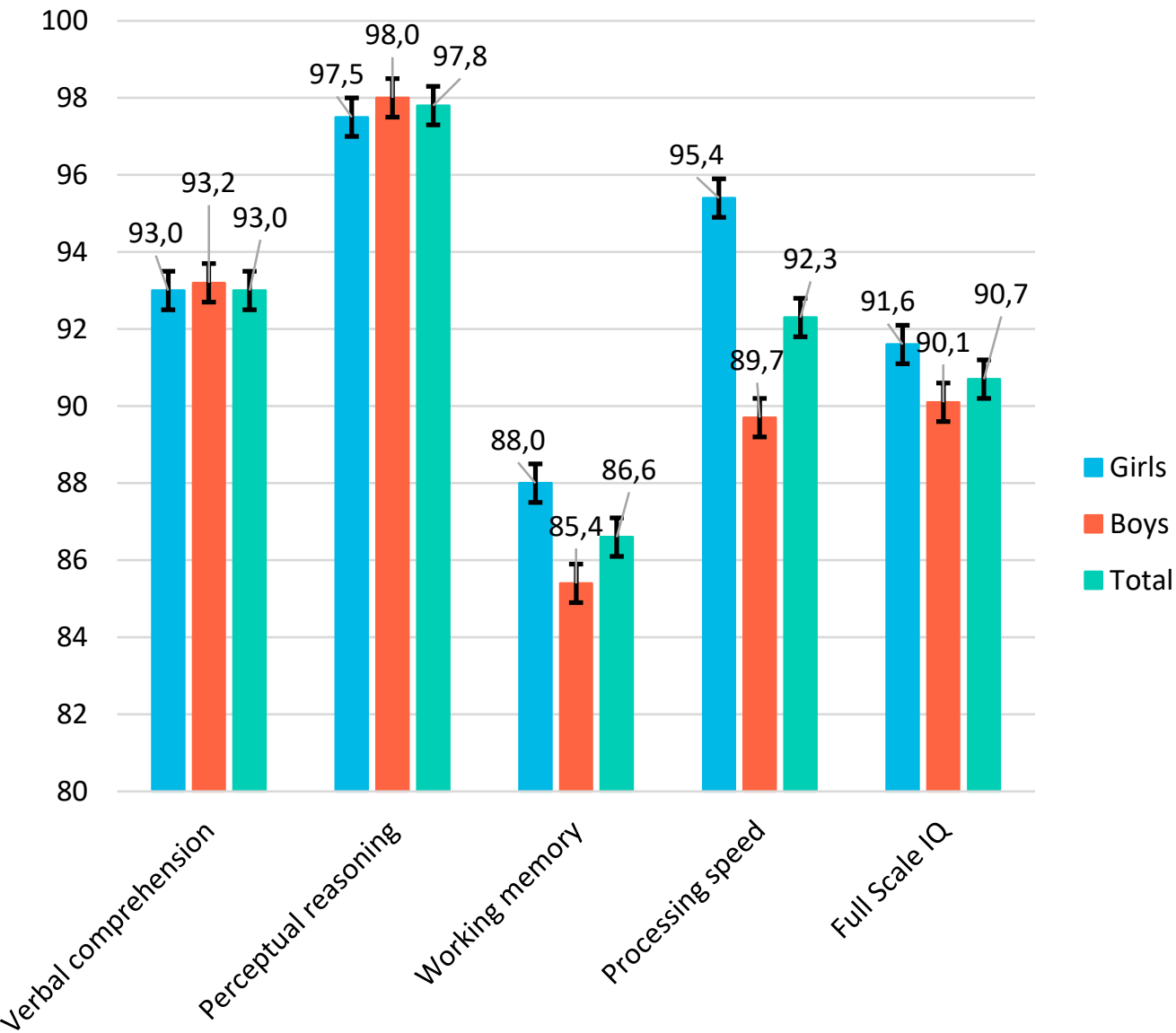


There were gender differences, i.e. boys scored poorer in working memory ( 85.4 vs. $88.0, p=0.010)$, processing speed ( 89.7 vs. $95.4, p<0.001)$, and sentence chains ( 3.60 vs. $3.96, p=0.037)$. In mathematic skills, boys outscored girls ( 3.77 vs. $3.35, p=0.011$ ), even though still far below means for their age norms. According to native language, in-group comparisons showed that there were no differences in intelligence, after controlling scores for obvious bias from verbal tests. Figure 8 .

\section{Follow-up tests of intelligence, literacy and mathematics}

The follow-up tests two years after inclusion in the Skolfam program revealed positive changes in all intelligence index scores $(d=0.211-$ $0.423)$, sentence chains $(d=0.211)$, reading comprehension $(d=0.364)$, spelling $(d=0.127)$ and mathematics $(d=0.194)$. Figure 10. Other results, such as letter-, digit-, and word chains, and word recognition revealed no significant change. Results in reading speed showed a decline from stanine mean 4.13 (S.D. $=1.98)$ to $3.92($ S.D. $=2.01)$. Figure 11.

In Figure 9 A-D, some of the results showing improvements are presented on a standard distribution curve, to visualize how the means relate to the whole age-standardized population. The scale used is z-value, representing a distance from norm mean $(\mathrm{z}=0.0)$, where 1.0 represents a full standard deviation. This makes crude comparisons possible between, in this case, the Wechsler and the Stanine scales. 
Figure 9. Changes in means between test 1 and 2 in Paper IV in Intelligence (A), Sentence Chains (B), Reading Comprehension (C), and Mathematics (D).

A)

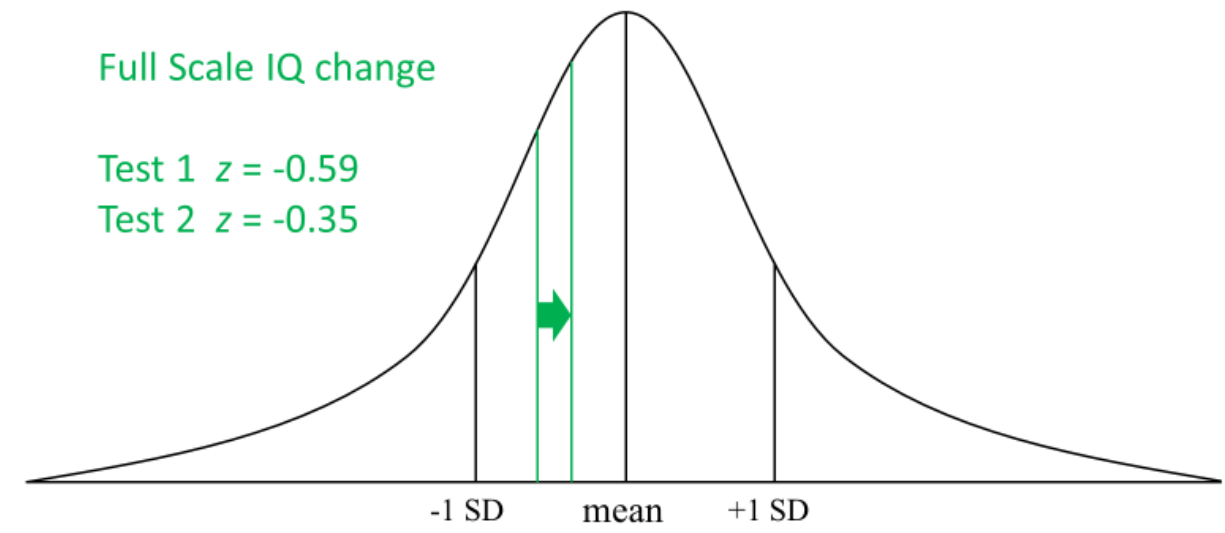

B)

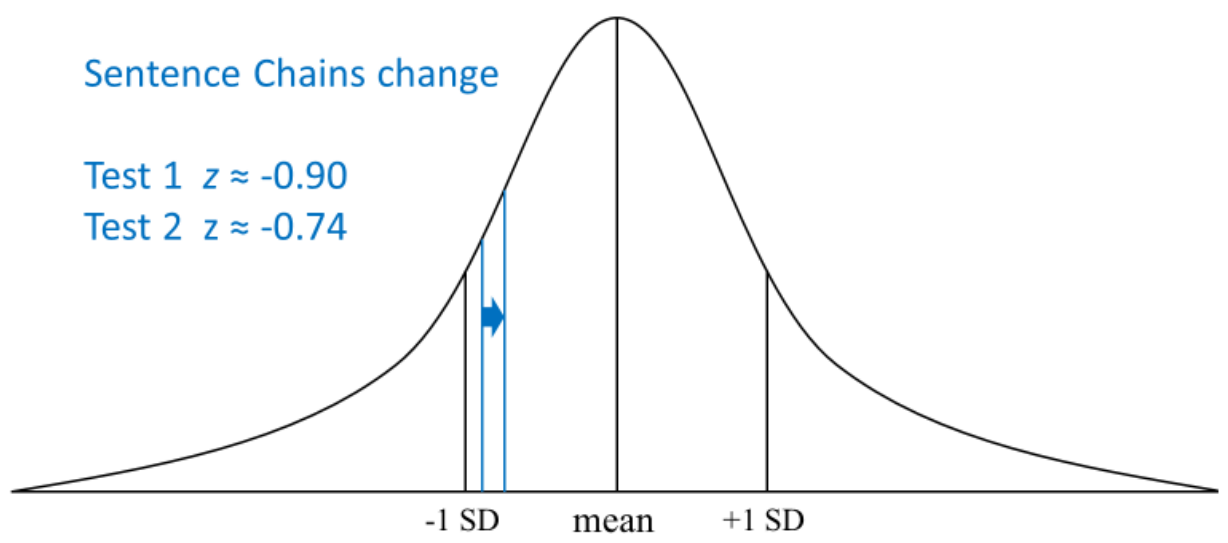


C)

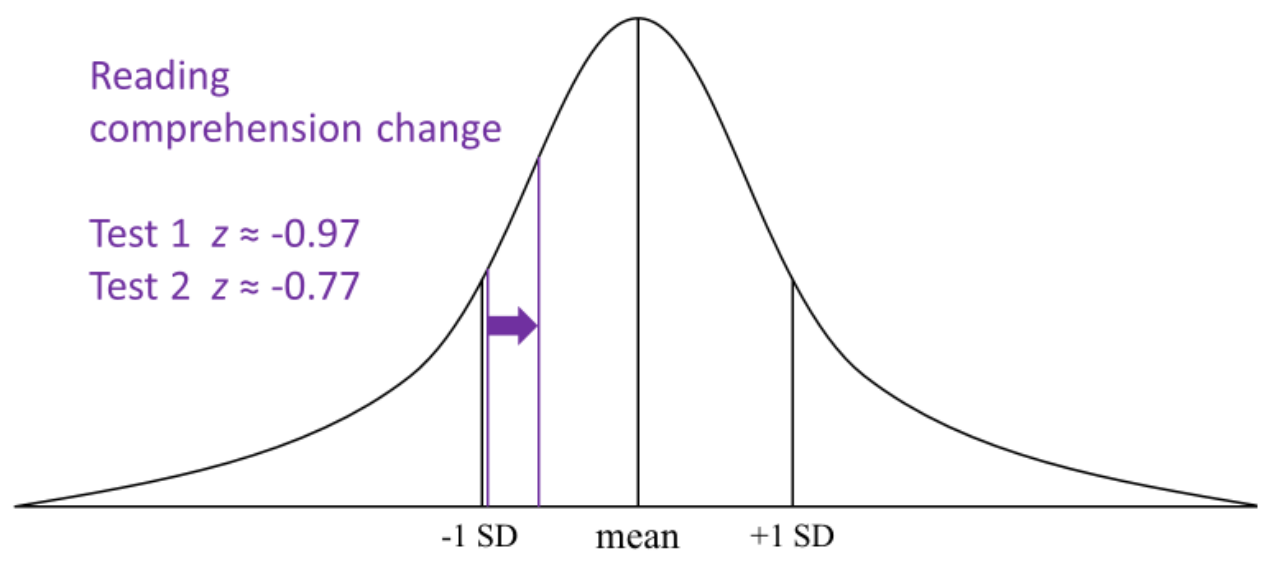

D)

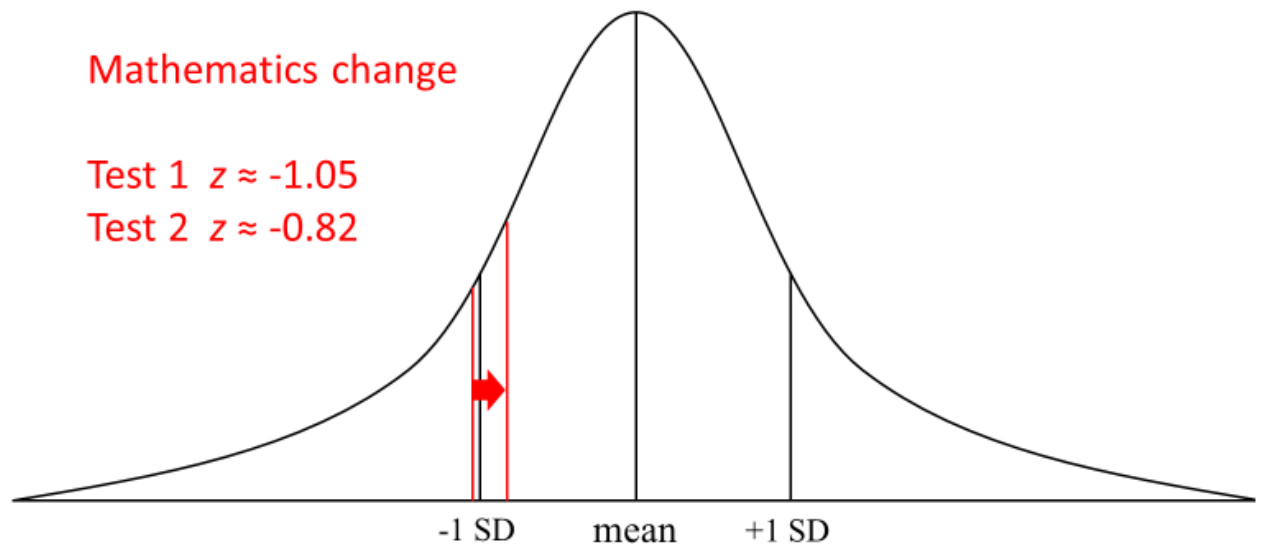


Figure 10. Means (Wechsler) from repeated tests in intelligence and adaptive behavior $(n=329$ - 419).

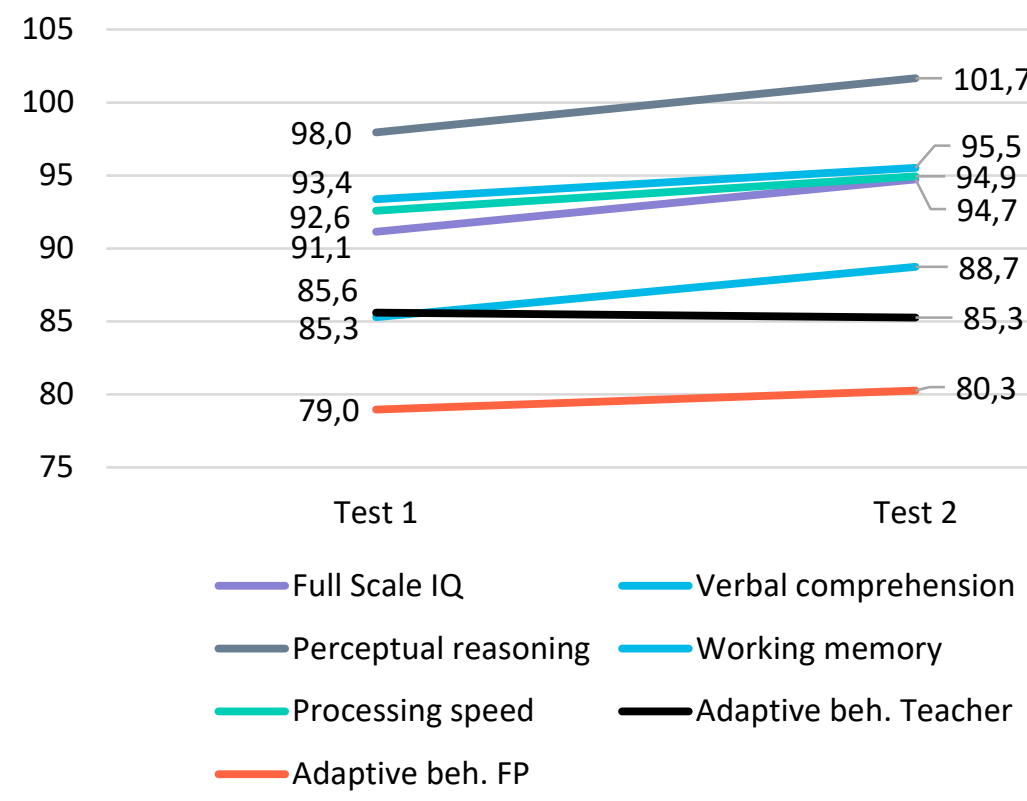

Figure 11. Means (Stanine) from repeated tests in literacy and mathematics $(n=59-406)$.

4,5

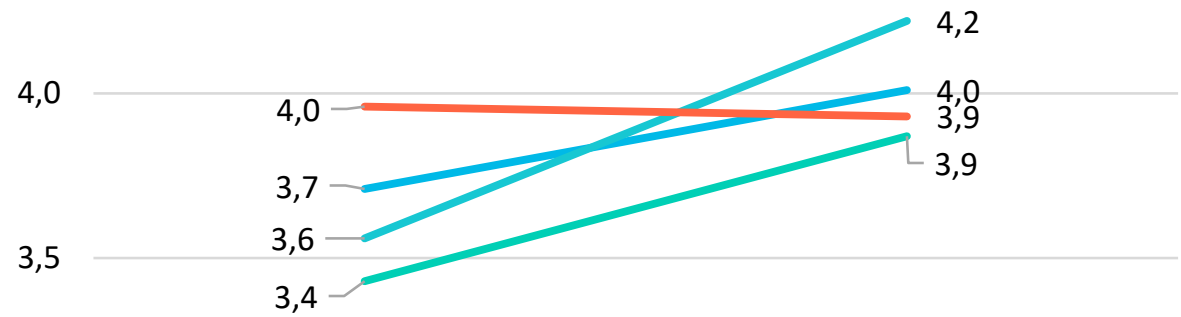

3,0

Test 1

Test 2

Sentence Chains

Reading comprehension

Mathematics

Word chains 


\section{Discussion}

The studies of children in $\mathrm{OHC}$ are performed from the aspects of health and wellbeing, and preconditions to school performance in different ages. They address knowledge gaps in details of vulnerability, such as online exposure to abuse, sought mental healthcare in specific diagnostic domains, different categories of abuse experiences, and specific preconditions in executive and affective functioning that possibly influence school performance. It also provides a plausible pattern of preconditions for the developmental pathway for children in OHC. In the following section, eight main findings are discussed.

\section{Health and wellbeing}

\section{More sought mental health care in most categories}

The finding of higher shares of seeking help in healthcare for mental problems for pupils in $\mathrm{OHC}$ was not surprising. This area has been studied before (Ford, Vostanis, Meltzer, \& Goodman, 2007; Goemans et al., 2016; Vinnerljung \& Sallnäs, 2008) and our results contribute to further validate evidence of a group more burdened with poor mental health. A recent study by Baldwin et al. (2019) disentangled the effect of OHC on child mental health by comparing mental health in three groups involved with child welfare services due to maltreatment; in $\mathrm{OHC}$, reunified, and those never in care. The authors did not find a significant difference in mental health $(\mathrm{AOR}=1.24, p=0.462)$ between the OHC group and those never in care. Their findings provide support to the growing consensus that poor mental health among children in care is not primarily an effect of the OHC itself, but rather a cumulative effect of previous maltreatment and other stressors (Cecil, Viding, Fearon, Glaser, \& McCrory, 2017; Wade et al., 2016). One exception was noted in the Baldwin et al. (2019) study, the prevalence of Reactive Attachment Disorder that was found higher in the OHC group, compared to the group statistically balanced equally maltreated, but not in OHC. This epidemiological anomaly was previously described by Lehmann, Breivik, Heiervang, Havik, and Havik (2016), and provides another clue to the understanding of the nature of poor mental health in children reared in $\mathrm{OHC}$.

Our results from Paper I, showed higher shares of almost all types of mental problems, except for autism spectrum disorder. 


\section{Higher risks for abuse experiences}

Earlier studies have established convincing evidence of children in $\mathrm{OHC}$ as exposed to higher risks for abuse experiences. For example, Courtney, Piliavin, Grogan-Kaylor, and Nesmith (2001) reported results from an interview study of 141 care leavers in Wisconsin, transferred to independent living at age 18. They found that $57 \%$ had experiences of physical abuse and $31 \%$ had experiences of sexual abuse. In their study, neglect in care was the most common detrimental experience by the respondents. Greger, Myhre, Lydersen, and Jozefiak (2015) studied a group of 335 adolescents (mean age 16.8 years) living in residential care in Norway, where exposure to maltreatment was $71 \%$. Victims of family violence were found in $46.4 \%$ of girls and $27.3 \%$ of boys. Being a victim of sexual abuse was experienced by $40.8 \%$ of the girls and $6.5 \%$ of the boys. In the Norwegian study, an odds ratio of 3.8 for any psychiatric diagnosis was found among the victims of sexual abuse. For victims of family violence, an odds ratio of 2.4 for anxiety diagnoses was reported.

In comparison, our findings were similar. Physical abuse reported by 50.0 $\%$ and sexual abuse by $31.4 \%$. Naturally, there are variations between different populations, but the big picture is the gap to children not in need of $\mathrm{OHC}$, in combination with other factors contributing to a worse prospect of recovery, for example, less trust to caregivers and in many cases a weaker social network. The novelty in our studies addresses the knowledge gap of severity in abuse for children in OHC, which affects the risk of an abusive event going from potentially traumatizing to traumatizing. The analysis revealed that although the share exposed to any sexual abuse was higher among pupils in $\mathrm{OHC}$, the gap was considerably wider in the more severe forms, penetrative abuse, and repeated sexual abuse. If this example of higher severity in one specific form of abuse is a piece of a more general pattern, it can provide a plausible cause to higher shares of posttraumatic syndrome disorder among children in $\mathrm{OHC}$, which would be an important hypothesis to test in further studies.

Prevalence of exposure to online abuse for children gained a scientific interest in the first decade, following a study by Mitchell, Finkelhor, and Wolak (2003). Today, we know more about how common online sexual abuse is, how it affects girls and boys and we are beginning to understand how trends in online sexual abuse change over time. For example, this year 2020 we will have the first longitudinal follow-up in Sweden after the 
global \#metoo movement, which raised common awareness of sexually abusive behavior among the general public population.

The contribution to the literature about online abuse concerns how it affects adolescents in OHC specifically, related to peers not in OHC. In Paper II, results showed that children in $\mathrm{OHC}$ more often reported exposure to social media abuse both in the form of spreading of sensitive material, and unwanted sexual contact attempts. The difference between adolescents in birth parent care and $\mathrm{OHC}$ was bigger in responses reflecting repeated exposures, indicating the same severity amplitude and poly-victimization tendency as observed in physical and sexual abuse in Paper I. It is more a reflection than a substantiated conclusion, that when bad events occur to children in $\mathrm{OHC}$, they tend to be more severe or repeated, not only affecting to a larger extent.

\section{Non-binary gender and sexual orientation}

The findings that were possible to use in general syntheses, spanning over two studies, came from the background data and relates to non-binary gender. Among the respondents to Paper I in birth parent care, $0.9-1.0 \%$ regarded themselves as non-binary gender. In the "Young, Sex and Internet" survey from 2014, three of $41(7.3 \%)$ in $\mathrm{OHC}$ claimed that the division boy/girl did not fit them. The small sample made conclusions from this sole study impossible but raised the interest to investigate in a larger sample. In the "Om Mig" sample in Paper II, there were ten of 311 (3.3\%) stating a non-binary gender. When comparing the two sources to information, it should be noted that Paper II included a younger sample, where $55 \%$ were 14 years old, compared to "Young, Sex and Internet" in Paper I, where the mean age was 18 . Thus, the difference in shares might be a result of measuring early versus later in the gender identity development progress between 14 and 18 years.

Gender nonconformity and non-binary gender is associated with a higher risk for mental health problems (Mustanski \& Liu, 2013; Toomey, Ryan, Diaz, Card, \& Russell, 2010) and should, therefore, be noted as a possible contributing factor to the higher risk of abuse and poor mental health among children in care. Given the relatively higher prevalence compared to adolescents in the normal population, gender non-conformity and nonbinary gender could be useful to include both in regular follow-up discussions in social service routines with adolescents in OHC but also included in research projects where respondents are adolescents in OHC. This practice is supported in the advice from the American Academy of 
Child and Adolescent Psychiatry (AACAP) Committee on Quality Issues, which have published nine principles to guide clinicians and practitioners in service with children and adolescents with gender non-conformity (Adelson, 2012).

The question of why there seems to be a higher correlation between nonconformity or non-binary gender among adolescents in OHC, compared to adolescents not in care is not possible to disseminate with data from our studies, but raise a research interest.

The higher share of other than heterosexual orientation among children in OHC in our Paper I, $31.8 \%$ is similar to a study by B. D. M. Wilson et al. (2017) studying youth prisoners 18 years age and above in U.S. correctional facilities. There are other studies (Plöderl \& Tremblay, 2015; Priebe \& Svedin, 2012) reporting more mental health problems and lower self-esteem in children and youth with a non-heterosexual orientation, making this statistical anomaly relevant. Other studies have reported shares closer to the whole population of non-heterosexual orientation among children in care, for example, B. D. M. Wilson and Kastanis (2015) reported $19 \%$ non-heterosexuality among Los Angeles foster care children close to age 16 . Studies including younger children found $15.5 \%$ lesbian, gay- or bisexual in children involved in child care (Dettlaff et al., 2018). Yet another study, Fish, Baams, Wojciak, and Russell (2019) have found support in U.S. national registry data for overrepresentation of sexual minority youth in child welfare studies. Based on these studies, there is support for a higher representation of sexual minority youth in OHC, as well as signs of an age gradient where overrepresentation for sexual minority orientation for children in care are less marked in younger adolescence and more marked among late adolescence, plausibly following the sexuality development pathway during adolescence.

\section{Less satisfaction with friends, family life and leisure time}

In Paper II we found that pupils in $\mathrm{OHC}$ reported being less satisfied with friends, leisure time, parents, and school than their peers not in care. When comparing to pupils living with a single birth parent, the difference was less marked concerning friends and school satisfaction but remained for leisure time and family. Hypothetically, his might suggest the effect being related to the degree of 'parental deprivation' or the strength in social or habituated bonds that have been broken in the placement process. Leisure activities and family life is influenced to a certain degree from parents' 
interests and commitment and passed along to children in close relation socialization, compared to friends and school, where changes are more common. Friends come and go and school satisfaction varies over time dynamically for most children. But family relations and commitment to leisure activities such as favorite sports or cultural activities might vary less over time and form stronger social, emotional, or habituation bonds. When such bonds are broken, the satisfaction with the replacement might be weaker or require a longer time to tie. The hypothesis of "broken bonds replacement satisfaction" would need to be further disseminated in studies with a phenomenological design.

\section{Poorer trust to non-professional adults, but equal trust to professionals}

Pupils in OHC expressed in Paper II less trust to parents, and tendencies to less trust to friends when turning to someone with problems or concerns. On the other hand, when asked about trust in turning to teachers, counselors, and health care staff, there was no significant difference. The shared properties for friends and family members are that the trust relies on a relational investment. The other categories in this matter have a formal or institutional trust embedded in their professional role. To confide something sensitive to a friend one has known for a couple of months is associated with social risk, but to confide to a nurse is less hazardous since there are legal and ethical rules regulating confidentiality and responsibilities to the professional role, rather than to the person. In analogy to the reasoning concerning satisfaction, this would impact adolescents in $\mathrm{OHC}$ and birth care differently. If trust is the product of learned experiences of relation fidelity, it would naturally be weaker among individuals with experiences of at least one bereavement in close relations, and often more than once in the case of OHC children. But not necessarily affecting trust to professionals.

\section{Less perceived security in the school and at home}

The results in Paper II regarding perceived security in the school and at home was discouraging, from the in loco parentis perspective. More than one in four of adolescents in OHC felt secure in school less than often, and more than one in five felt secure at home less than often. Compared to peers in birth parent care, the expressed insecurity was twice as high in school and five times higher at home.

Using the theoretical framework of Bronfenbrenner's microsystem (Bronfenbrenner \& Ceci, 1994) supporting the growth of trust and security 
in close relations, the sense of security is the fundament for further learning and development. Security is fundamental in a way that for most, is taken for granted. But without perceived security, it becomes the primary focus of attention.

A previous Swedish study, Sallnäs, Wiklund, and Lagerlöf (2012) did not find differences regarding feeling secure in the neighborhood day or night for children in foster care compared to peers in the whole population. This could be understood as two completely different environments, where the Sallnäs study relates to the surroundings to the household and the potential threats from individuals outside the family and the school environment, whereas questions in the "About Me" survey relates to perceived internal threats within the social networks of the school or the family. 


\section{School performance for children in $\mathrm{OHC}$}

\section{Considerably lower mean scores in intelligence, particularly working memory}

In Paper III test results were compiled from 856 children in foster care from the Skolfam assessments in Sweden. Previous studies of school-related conditions such as intelligence in $\mathrm{OHC}$ children have been either based on very small samples, heavily burdened children (Almas et al., 2016), or cross-sectional studies of registry data from draft board assessments before military service. We expected slightly lower means in IQ due to the stress impact on neural and endocrinal development that many children in $\mathrm{OHC}$ have experienced. Also, previous studies with smaller samples have found lower means. For example, total index means of around 90 (Durbeej \& Hellner, 2017; Tordön et al., 2014), and working memory as the lowest index mean (83.3 in Durbeej \& Hellner and 88.8 in Tordön et al.). Results in this larger sample confirmed total IQ means of around 90 and working memory around one full standard deviation below norms. Perceptual reasoning was the index closest to norm means, in line with earlier findings in smaller samples.

The same pattern of lower scores in literacy and mathematics tests were found in the compilation, again confirming results in previous studies (Durbeej \& Hellner, 2017; Tideman et al., 2011; Tordön et al., 2014). In Paper III, there was enough statistical power to also make reliable in-group comparisons, where results showed that boys scored worse in almost every measure, except for mathematics. There was no significant difference between children regarding their native language, after controlling for the influence of poorer verbal skills, except for less adaptive behavior problems among those with foreign native language.

In Paper III the conclusions were that children in OHC should not be assumed to follow age-typical conditions to prevail in school but should be individually assessed to make sure that education is tailored to fit their specific needs. Their poorer preconditions may have many reasons, from epigenetic vulnerabilities to multiple traumas, from the absence of books in their homes to the absence of caring parents before they were taken into care. Or, they simply have knowledge gaps as a result of the transfer between schools. Bottom line is that school, social services, and healthcare have no valid evidence of what to expect from individual children until conditions and status is assessed individually. The group as a whole is more burdened than their peers not in care, but the variance and the nature of their challenges cannot be assumed without individual assessments. Furthermore, there are individual strengths to find in individual children in 
OHC. These strengths are just as necessary to identify as the gaps and problems, for making a plan with prospects for success.

\section{Interventions can change conditions for school performance}

Paper IV followed up on the sample in Paper III, to explore how conditions for school performance change after the initiation of a working model adding specific support above the foster care itself. The main findings from Paper IV were:

- Higher-order executive functions, literacy, and mathematic skills improved when individual assessments, followed by adaptations meeting the individual needs for children in foster care were applied. Figures 9 or 10.

- Lower-order executive functions and affective functioning did not change automatically following progress in higher-order executive functions among children in foster care.

- Psychosocial wellbeing showed to be more pervasive to change from a school-oriented intervention and might need a dedicated method to improve.

As stated by Leve et al. (2012), there exist interventions aiming to improve resilience to detrimental processes among children in foster care, showing promising efficacy, but they are poorly evaluated outside the US and the utilization is unclear. Related to the findings in the included study, interventions targeting both the negative socio-emotional outcome and the school performance is needed. The included study have shown that there is a weak link, if any at all, between improved higher-order executive functions and affective functioning, leading to the conclusion that interventions aiming to improve school performance cannot be expected to also improve affective or socio-emotional function. This conclusion implies that further research on the transfer of effects between executive and affective function is needed. In child welfare practice, models that target both areas, together or respectively should be considered in the $\mathrm{OHC}$ policy.

In the absence of evidence of causal explanations to the processes leading to poorer health and school performance for children in $\mathrm{OHC}$, interventions can be designed to address needs on a pragmatic level. For example by training programs in literacy and numeracy skills, as in the Letterbox Club program (Griffiths, 2012) or general and standardized broad assessments followed by targeted interventions based on the assessment, as in Skolfam 
(Tideman et al., 2011). Or physical activity interventions aiming to improve health. For a recent review please see B. Wilson and Barnett (2020).

Intervention research has been conducted, mostly with small samples and inadequate designs to assess efficacy, but there are also examples of studies with stronger designs (Durbeej \& Hellner, 2017). A promising study protocol for a systematic review of interventions and practice models for improved health and psychosocial outcomes was published recently (Galvin, O'Donnell, Skouteris, Halfpenny, \& Mousa, 2019). Another recent study (Brännström, Forsman, Vinnerljung, \& Almquist, 2020) found that cognitive ability for children in $\mathrm{OHC}$ at age 13 was the main explanatory factor to educational achievement in $9^{\text {th }}$-year compulsory school and midlife educational attainment at age 50, suggesting that improving cognitive abilities early could be a way to improve both shortterm achievement and long-term attainment for children in $\mathrm{OHC}$.

In a UK register study, Sinclair, Luke, and Berridge (2019) found that already at the age of seven, children looked after by the state (CLA), as well as children deemed in need but not in care (CIN), had school attainment approximately one standard deviation below the cohort average. From age seven it then gradually fell relative to their peers. Removal from home to care did halt or reduce the decline but did not reverse the negative development.

Studies of organizational models of health services for children in OHC, with acceptable quality, are absent according to a recent literature review (Mensah et al., 2020).

A recent Australian study, using data from the New South Wales Child Development Study (Laurens et al., 2020), compared $3^{\text {rd }}$ and $5^{\text {th }}$ graders reading and numeracy skills in different levels of child protection involvement in a fully adjusted model controlling for other adversities or plausible detrimental covariate factors. From $\mathrm{OHC}$ to children with substantiated risk of significant harm (ROSH), unsubstantiated ROSH, non-ROSH, and no child protection report. All children with child protection reports were more likely to score below their peers in reading and numeracy. Children with substantiated ROSH but not in $\mathrm{OHC}$ demonstrated the worst educational attainment, and there was some evidence for positive effects for children taken into $\mathrm{OHC}$. 


\section{General discussion}

The studies in this thesis have advanced specific knowledge on different aspects of adverse conditions for children in OHC. In literature, there is a vast knowledge about children in $\mathrm{OHC}$ concerning general broad conditions, related to conditions in the whole population. Registry studies (Björkenstam et al., 2015; Forsman, Brännström, Vinnerljung, \& Hjern, 2016), medical- and social journal studies (Lightfoot, Hill, \& LaLiberte, 2011) provide a picture of a group with higher risks for adverse outcomes, from missed child healthcare appointments (Randsalu \& Laurell, 2018) to suicide (Vinnerljung, 2012). Studies with a qualitative or case study methodology also provide an understanding of how children in care themselves perceive their situation (Höjer \& Sjöblom, 2014) and how they participate in assessments and legal processes (Heimer, Näsman, \& Palme, 2018).

The studies included in this thesis contribute to advance knowledge in specific areas of deficits or adversities. For example, different types of abuse, poly-victimization, and to what extent children in OHC disclose adverse events to adults. Results from the studies in this thesis also contribute to filling gaps in describing the variance in OHC children's performance in different school subjects, and how their performance relates to other factors such as gender, native language, or executive functioning.

Finally, the results in this thesis provide support to the development of more efficient interventions aiming to improve school performance among children in $\mathrm{OHC}$.

\section{Relevance}

Children in OHC belong to a group that has higher risks for adversities and poorer conditions than peers. Therefore, the higher group risks call for the application of individual assessments, but not to alter expectations on individual $\mathrm{OHC}$ children before assessments are done.

Practitioners in healthcare and social service need to make sure not to have any preconceptions about normality when meeting children in OHC. The studies show that problems related to health, social life, perceived security, and abuse are more common in this group. Above that, children in $\mathrm{OHC}$ tend to be less prone to disclose problems or adversities to parents but might disclose to professionals. 
For practitioners in school education, the findings show that children in $\mathrm{OHC}$ are better served by individual assessments to find their skills, their gaps, and on what level expectations ought to be. For a more efficient teaching practice, it is also relevant to know that higher-order executive functions in this group of children show the potential for improvement.

For individuals with personal experience from $\mathrm{OHC}$, as foster parents, or from being in care oneself, this thesis is relevant for a better understanding of the conditions you create and are affected by. Some circumstances make life more difficult when children are taken into care, but many of them are possible to improve.

\section{Recommendations to practice}

There are development and evaluation initiatives concerning support to children in $\mathrm{OHC}$ or exposed to abuse. At Uppsala University, for example, the computer-aided child interview "In My Shoes" (Fängström et al., 2016), supporting the child's accounting for experiences that are not easy to disclose.

Another promising tool to use in regular follow-up in social work with OHC children is Computer-Assisted Self interviewing (M. Davies \& Morgan, 2005), which has shown to be well accepted by OHC children in the UK (Morgan \& Fraser, 2009). A recent development is the highly modular "MyView-app" (W. Davies, 2020), developed by the Viewpoint organization and used in UK, Ireland, Western Australia (Garsed \& Davies), and Canada. Viewpoint is presently (April 2020) undergoing pilot testing in the Swedish municipalities Hägersten, Gotland, and four other municipalities.

To practitioners in school, the recommendations are to assess skills and knowledge among pupils in $\mathrm{OHC}$ more frequent and more in-depth, to find individual strengths and gaps that can adjust expectations and increase chances of success in everyday schoolwork. It is also recommended that you provide the support your $\mathrm{OHC}$ pupils need to make progress in literacy and mathematics with a long-term perspective. School failure must be avoided at almost any cost.

Foster carers are recommended to encourage and support schoolwork as much as possible, provide a secure environment, and protect the children from abuse of any kind. When there are problems, support children in assessing what is wrong, and never make any assumptions of conditions to be deterministic. 


\section{Strengths}

This thesis builds on three different data sources but with one common theme across the studies, children and adolescents with the shared experience of OHC. Age-wise, they cover compulsory school age, 14-yearolds in early adolescence, 16-year-olds in mid-adolescence, and 18-yearolds on the threshold to adulthood. This provides a wider base and adds to validity.

The large sample sizes were a necessity in the survey studies. Index groups were 41 and 311 which allowed for reliable statistic calculations where the latter also could provide for the possibility to make in-group calculations. In the Skolfam studies, Paper III and IV, the sample size also allowed for more reliable data, especially in the ingroup analyses. It was possible to relate the results to two earlier local evaluations (Tideman et al., 2011; Tordön et al., 2014) and one larger national evaluation with a quasiexperimental design (Durbeej \& Hellner, 2017), adding to the validity of the Skolfam model.

In all four studies, children or adolescents themselves were used as primary informants, even though the Skolfam instruments also included teacher and foster parent assessments. Most of the quantitative studies on children in $\mathrm{OHC}$ are based on secondary data from medical records, national registries, social workers, teachers, residential home care workers, or foster parents. Also, most of the data originated from direct measures of conditions as they appeared directly, whereas only a few items in the survey studies regarded recalled memories retrospectively. This minimizes measurement bias from interpretations via secondhand sources or flawed memories.

In the Skolfam studies, the use of age-standardized instruments with peerreviewed standardization studies, provided norms that could be related to our results, adding to the reliability of the results.

\section{Limitations}

The survey studies were influenced by selection bias. Paper I was based on a survey directed to pupils in the last year of upper secondary school. From national registry data, we knew that around two-thirds of children in Swedish OHC did not finish upper secondary school and around $40 \%$ did not proceed further than compulsory school. Nevertheless, this was known from the beginning and subsequently treated as a fixed study parameter. 
Therefore, results could not be generalized to be valid for all Swedish OHC 18 -year-olds, but only those that attended $3^{\text {rd }}$-year upper secondary school.

Paper II study was also influenced by selection bias, but to a lesser extent, since $54.7 \%$ of respondents were in compulsory school. This study was also affected by measurement bias related to two of the questions being ambiguous asking about parents and family, without further definition.

The most serious limitation in Paper III and IV studies was the lack of a matched control group of children in foster care not given the studied intervention. This makes a generalization of the effects hazardous.

In general, the studies contained insufficient background information on pre-placement experiences to make conclusions about causality to the deficits expressed in the results. Thus, we do not know, for example, if the poorer working memory or the higher extent of sexual abuse was related to experiences before or during the care.

\section{Method considerations for health-, abuse-, and wellbeing aims}

The first two studies had aims and questions that could be answered by comparing a sub-sample of children in OHC, to their peers not in OHC. We needed data material that represented the normal population and with a large enough sample to have sufficient statistical power for making reasonable generalizations. Since the studied group of children in $\mathrm{OHC}$ represents only $1.6 \%$ of the population, we would need samples of around 3150 respondents to expect 50 of them to be in OHC. Considering the age distribution in $\mathrm{OHC}$ children, if samples were older, a smaller sample would be acceptable, but if samples were younger, we would need more. A complicating factor was that we knew school attendance after compulsory school to be considerably lower among OHC children. This would increase the demands of larger sample sizes using data from pupils in upper secondary school. As it turned out, the first study of 18-year-olds in upper secondary school resulted in $41(0.7 \%)$ pupils in OHC of the total 5839 respondents. In comparison, close to $4 \%$ of Swedish youth in ages 15-20 in the year 2018 were in $\mathrm{OHC}$, which in turn raises questions about skewed dropout in the sample.

Ideally, data would include background questions specifically interesting for further categorizing children in OHC. For example, type of placement, age at first placement, the number of transfers between different care facilities, adverse experiences before or during placement, or birth parent's 
socio-economic and educational status. This could have been done by developing one or two web surveys specifically for the aim of studying children in $\mathrm{OHC}$.

A specifically designed national web survey would enable more in-depth questions with a more specific background, answer options, and follow-up questions of interest. On the other hand, a minimum of 3000 respondents would be required for a sample that enabled analyses of at least in-group comparisons of two similar shares, for example, boys and girls. Response rates would need to be above around $60 \%$ for valid conclusions. Open web- or social media invitations to surveys have the potential to attract many responses, but with limitations regarding analyses of distribution among intended target groups, which was the main reason to why we did not proceed with a new web survey.

Qualitative methods, with interviews of children in OHC, would provide a very good in-depth understanding of detrimental events or conditions from the child's perspective, as well as resilience or protective factors. The drawback to such methods is aspects of generalizability. They are suited for studies aiming to inform new hypotheses or deepen the understanding of details in phenomena already known to be a common trait in a certain group. A study with that methodology would indeed have been beneficial to this thesis as a complement to the instrumental data provided by the other studies. In a way, there is always novelty in qualitative studies, but we aimed to explore characteristics for the group of OHC children, rather than individual perceptions. Hence, we did choose quantitative methods.

\section{Method considerations for the studies of school performance}

The aims related to school performance were mainly in the cognitive and educational domains of development for children in OHC. The literature so far has described broad markers of poor school performance such as lower mean grades (Pecora et al., 2006; Vinnerljung, Öman, \& Gunnarson, 2005), poorer literacy (Griffiths, 2012; Poulton \& National Literacy, 2012), or attainment levels (Kaariala et al., 2018; Luke \& O'Higgins, 2018; Okpych \& Courtney, 2014; Sebba \& Luke, 2019). We aimed to explore in more detail the aspects of poor school performance by studying assessments of specific features close to what is assessed in daily school practice. For example, not only a general IQ score from a screening instrument but different indexes reflecting the variance between different components within the total intelligence score. Or literacy beyond a crude 
single measure by exploring text decoding, word comprehension, and reading comprehension as separate components.

By compiling locally stored data, we were able to build a data set that could be analyzed to explore the specifics in different aspects of conditions for foster care children in school, before and after two years of a school-based intervention. The instruments were age-standardized, therefore comparisons of means with norms could be done.

Alternatively, we could have staged a study of school reports (grades) for a stratified sample of children in OHC. This would have had the benefit of including a control group of children not in $\mathrm{OHC}$, and we could have made a longitudinal design studying the progression over time. The downside of such a design would be that the data would be of end outcome rather than preconditions, and therefore not adding novel knowledge to guide new and more efficient interventions.

In the chosen method, we lack data that would have provided a more indepth analysis. For example, basic background data of parents, cause to the placement in care, specific interventions in school, utilization of healthcare or adverse experiences preceding or during care. Or, qualitative data from children on how they perceive school, what they see as obstacles, and resilience or supportive factors in their school progress. Future research would benefit from broader sources to more specific hypotheses about possible causal detrimental or resilience factors related to $\mathrm{OHC}$ children's poorer outcomes.

\section{Ethical reflections}

There are ethical considerations worth raising related to the aftermath of the studies. This does not apply to autonomy, informed consent, or nonmaleficence since we have no indication of any participant being coerced or harmed during either the data collection by us or in the primary data collection for the surveys and assessments. Related to the demands of justice in research practice, there are concerns if it can be stated that participants were given access to the best care proven after study completion. Through the studies, adversities in health and educational deficiencies were discovered in $\mathrm{OHC}$ children and pupils. Since the surveys were anonymous, there were limited possibilities to guide subjects further for support. In future studies of this vulnerable group, one must balance the drawbacks of anonymous data collection against the benefit for 
identified participants to receive proper beneficial support. And in the Skolfam studies, a recurrent comment from participating children in the annual surveys is that this intervention should be available to all their peers.

Justice in research practice also relates to balancing ethics regarding not performed research and consequences of poor interventions in regular practice. Medical and social work research often focuses on problems, deficiencies, and adversities. Mostly by describing prevalence or perceptions of the subjects or, rarer, the outcome of different interventions. When knowledge fails to progress as a result of research not performed, it becomes an ethical issue.

On the sociological, or policy level, there is a need to further describe the political and economic revenue gains of preventive interventions for improved health and educational performance for children in OHC. There is also a need to apply structured methods with the highest standards to evaluate effects on interventions. Such research initiatives do raise ethical obstacles, for example regarding randomization to control groups or handling sensitive information including personal code numbers and welfare costs. The alternative, to refrain from taking that methodological and ethical challenge, could be regarded as continued and prolonged harm. 


\section{Implications for future research}

Building on the results from the two first studies, we can formulate new hypotheses to inform the design of future research projects. Most importantly, we can give some basic suggestions on how future research designs could be set up.

First, we need more longitudinal studies on health and wellbeing among children in $\mathrm{OHC}$, where children are monitored over several years to discover developmental processes that can be analyzed building on a strong methodology that allows valid generalizations and with sufficient background data to recognize where the detrimental impacts occur. Before placement, related to the placement process, or after first placement.

Second, we need to collect data broadly from sociological, psychological, educational, and medical sources to discover when different factors occur and how they affect the outcome in sociological, psychological, educational, and medical measures.

Third, we need to use an experimental methodology to cross-analyze and randomize different individuals living under different conditions. And big enough study samples to get reliable data in the statistical analysis. 


\section{Conclusions}

To conclude, there are novel findings in the studies. Statistical anomalies regarding sexual orientation or non-binary gender for adolescents in $\mathrm{OHC}$ have not been studied in Sweden before and have not been in focus in the literature. The difference in how higher-order executive function, literacy, and mathematic skills improved, where the lower-order executive and affective functions did not improve following the school-based intervention, is also a novel finding. In respect to this, further development of methods to improve health and behavior is needed. Results can advance the knowledge on how support for children in $\mathrm{OHC}$ can be developed one step further.

The included studies also confirm earlier findings of children in $\mathrm{OHC}$ as a group exposed to poorer health, more abusive experiences, less trust in close social relations and poorer preconditions to achieve well in school. The findings also confirm results from previous studies on Skolfam as a model that can improve school performance for children in OHC. In these areas, the novelty lies in more specific descriptions of where the problems tend to be severe, and where improvements can be expected from interventions currently implemented in parts of Sweden. 


\section{References}

Adelson, S. L. (2012). Practice Parameter on Gay, Lesbian, or Bisexual Sexual Orientation, Gender Nonconformity, and Gender Discordance in Children and Adolescents. Journal of the American Academy of Child \& Adolescent Psychiatry, 51(9), 957-974. doi:https://doi.org/10.1016/j.jaac.2012.07.004

Almas, A. N., Degnan, K. A., Nelson, C. A., Zeanah, C. H., \& Fox, N. A. (2016). IQ at age 12 following a history of institutional care: Findings from the Bucharest Early Intervention Project. Developmental Psychology, 52(11), 1858-1866. doi:10.1037/dev0000167

Almquist, Y. B., \& Brannstrom, L. (2014). Childhood peer status and the clustering of social, economic, and health-related circumstances in adulthood. Soc Sci Med, 105, 67-75. doi:10.1016/j.socscimed.2014.01.011

Arango, C., Díaz-Caneja, C. M., McGorry, P. D., Rapoport, J., Sommer, I. E., Vorstman, J. A., . . Carpenter, W. (2018). Preventive strategies for mental health. The lancet. Psychiatry, 5(7), 591-604. doi:10.1016/S2215-0366(18)30057-9

Backe-Hansen, E., Højer, I., Sjöblom, Y., \& Storø, J. (2013). Out of home care in Norway and Sweden - Similar and different. Psychosocial Intervention, 22(3), 193-202. doi:10.5093/in2013a23

Baldwin, H., Biehal, N., Cusworth, L., Wade, J., Allgar, V., \& Vostanis, P. (2019). Disentangling the effect of out-of-home care on child mental health. Child Abuse Negl, 88, 189-200. doi:10.1016/j.chiabu.2018.11.011

Balen, R., Blyth, E., Calabretto, H., Fraser, C., Horrocks, C., \& Manby, M. (2006). Involving children in health and social research: 'Human becomings' or 'active beings'? Childhood, 13(1), 29-48. doi:10.1177/0907568206059962

Barnombudsmannen. (2020). Dom tror att dom vet bättre - barnet som rättighetsbärare. Retrieved from Stockholm: https://www.barnombudsmannen.se/globalassets/dokument-fornedladdning/arsrapport-2020.pdf

Becker-Blease, K. A., \& Freyd, J. J. (2006). Research participants telling the truth about their lives: The ethics of asking and not asking about abuse. American Psychologist, 61(3), 218-226. doi:10.1037/0003-066X.61.3.218

Belli, P. C., Bustreo, F., \& Preker, A. (2005). Investing in children's health: What are the economic benefits? Bulletin of the World Health Organization, 83(10), 777-784. Retrieved from https://www.scopus.com/inward/record.uri?eid=2-s2.0- 
26944484810\&partnerID $=40 \& \mathrm{md} 5=6 \mathrm{~d} 8121 \mathrm{e} 8 \mathrm{f} 1 \mathrm{e} 4 \mathrm{ddeec} 94061 \mathrm{fc}$ $6 \mathrm{c} 07 \mathrm{~b} 947$

Berger, L. M., Bruch, S. K., Johnson, E. I., James, S., \& Rubin, D. (2009). Estimating the "impact" of out-of-home placement on child wellbeing: Approaching the problem of selection bias. Child Development, $\quad 80(6), \quad 1856-1876 . \quad$ doi: $10.1111 / \mathrm{j} .1467-$ 8624.2009.01372.x

Berlin, M., Vinnerljung, B., \& Hjern, A. (2011). School performance in primary school and psychosocial problems in young adulthood among care leavers from long term foster care. Children and Youth Services Review, 33(12), 2489-2497. doi:10.1016/j.childyouth.2011.08.024

Bernard, K., Dozier, M., Bick, J., Lewis-Morrarty, E., Lindhiem, O., \& Carlson, E. (2012). Enhancing Attachment Organization Among Maltreated Children: Results of a Randomized Clinical Trial. Child Development, 83(2), 623-636. doi:10.1111/j.14678624.2011.01712.x

Bessell, S., \& Gal, T. (2009). Forming partnerships: The human rights of children in need of care and protection. International Journal of Children's Rights, $\quad$ 17(2), 283-298. doi:10.1163/157181808X358258

Bjorkenstam, C., Bjorkenstam, E., Ljung, R., Vinnerljung, B., \& Tuvblad, C. (2013). Suicidal behavior among delinquent former child welfare clients. Eur Child Adolesc Psychiatry, 22(6), 349-355. doi:10.1007/s00787-012-0372-8

Björkenstam, E., Dalman, C., Vinnerljung, B., Weitoft, G. R., Walder, D. J., \& Burström, B. (2015). Childhood household dysfunction, school performance and psychiatric care utilisation in young adults: A register study of 96399 individuals in Stockholm County. Journal of Epidemiology and Community Health. doi:10.1136/jech-2015-206329

Bonevski, B., Randell, M., Paul, C., Chapman, K., Twyman, L., Bryant, J., ... Hughes, C. (2014). Reaching the hard-to-reach: a systematic review of strategies for improving health and medical research with socially disadvantaged groups. BMC medical research methodology, 14, 42-42. doi:10.1186/1471-2288-14-42

Bos, K., Zeanah, C. H., Fox, N. A., Drury, S. S., McLaughlin, K. A., \& Nelson, C. A. (2011). Psychiatric outcomes in young children with a history of institutionalization. Harvard Review of Psychiatry, 19(1), 15-24. doi:10.3109/10673229.2011.549773

Briere, J. (1996). Trauma symptom checklist for children (TSCC) professional manual. Odessa: Psychological Assessment Resource. 
Bronfenbrenner, U. (1979). The ecology of human development: Experiments by nature and design. Cambridge, Mass: Harvard University Press.

Bronfenbrenner, U., \& Ceci, S. J. (1994). Nature-Nurture Reconceptualized in Developmental Perspective: A Bioecological Model. Psychological Review, 101(4), 568-586. doi:10.1037/0033-295X.101.4.568

Bronsard, G., Alessandrini, M., Fond, G., Loundou, A., Auquier, P., Tordjman, S., \& Boyer, L. (2016). The prevalence of mental disorders among children and adolescents in the child welfare system a systematic review and meta-analysis. Medicine (United States), 95(7), e2622. doi:10.1097/MD.0000000000002622

Brännström, L., Forsman, H., Vinnerljung, B., \& Almquist, Y. B. (2020). Inequalities in educational outcomes in individuals with childhood experience of out-of-home care: What are driving the differences? PLoS ONE, 15(4), e0232061. doi:10.1371/journal.pone.0232061

Bränström, R., Hatzenbuehler, M. L., Tinghög, P., \& Pachankis, J. E. (2018). Sexual orientation differences in outpatient psychiatric treatment and antidepressant usage: Evidence from a populationbased study of siblings. European Journal of Epidemiology, 33(6), 591-599. doi:10.1007/s10654-018-0411-y

Bäckman, O., Estrada, F., Nilsson, A., \& Shannon, D. (2014). The Life Course of Young Male and Female Offenders: Stability or Change between Different Birth Cohorts? The British Journal of Criminology, 54(3), 393-410. doi:10.1093/bjc/azu007

Cambridge Dictionary. Cambridge Dictionary. Retrieved from https://dictionary.cambridge.org/dictionary/english/

Cecil, C. A. M., Viding, E., Fearon, P., Glaser, D., \& McCrory, E. J. (2017). Disentangling the mental health impact of childhood abuse and neglect. Child Abuse \& Neglect, 63, 106-119. doi:https://doi.org/10.1016/j.chiabu.2016.11.024

Chamberlain, P., Price, J., Leve, L. D., Laurent, H., Landsverk, J. A., \& Reid, J. B. (2008). Prevention of behavior problems for children in foster care: Outcomes and mediation effects. Prevention Science, 9(1), 17-27. doi:10.1007/s11121-007-0080-7

Clark, H. B., Prange, M. E., Lee, B., Boyd, L. A., McDonald, B. A., \& Stewart, E. S. (1994). Improving Adjustment Outcomes For Foster Children With Emotional And Behavioral Disorders: Early Findings From A Controlled Study On Individualized Services. Journal of Emotional and Behavioral Disorders, 2(4), 207-218. doi:10.1177/106342669400200403 
Clausen, S.-E., \& Kristofersen, L. B. (2008). Barnevernsklienter $i$ Norge 1990-2005: en longitudinell studie. Oslo: Norsk institutt for forskning om oppvekst, velferd og aldring.

County of Östergötland. (2018). Om mig - webbenkät för unga. Retrieved from https://vardgivarwebb.regionostergotland.se/ungdomsenkat/

Courtney, M. E., Piliavin, I., Grogan-Kaylor, A., \& Nesmith, A. (2001). Foster youth transitions to adulthood: a longitudinal view of youth leaving care. Child Welfare, 80(6), 685-717. Retrieved from https://www.ncbi.nlm.nih.gov/pubmed/11817658

Davies, M., \& Morgan, A. (2005). Using computer-assisted selfinterviewing (CASI) questionnaires to facilitate consultation and participation with vulnerable young people. Child Abuse Review, 14(6), 389-406. doi:10.1002/car.925

Davies, W. (2020). MyView app. Retrieved from https://vimeo.com/387975737

Dettlaff, A. J., Washburn, M., Carr, L. C., \& Vogel, A. N. (2018). Lesbian, gay, and bisexual (LGB) youth within in welfare: Prevalence, risk and outcomes. Child Abuse Negl, 80, 183-193. doi:10.1016/j.chiabu.2018.03.009

Durbeej, N., \& Hellner, C. (2017). Improving school performance among Swedish foster children: A quasi experimental study exploring outcomes of the Skolfam model. Children and Youth Services Review, 82, 466-476. doi:10.1016/j.childyouth.2017.10.014

Elwér, Å., Fridolfsson, I., Samuelsson, S., \& Wiklund, C. (2013). LäSt Test $i$ läsförståelse, läsning och stavning. Stockholm: Hogrefe Psykologiförlaget AB.

Engström, A., \& Magne, O. (2003). Medelsta-matematik Hur väl behärskar grundskolans elever lärostoffet enligt Lgr 69, Lgr 80 och Lpo 94? Örebro: Pedagogiska institutionen.

Fish, J. N., Baams, L., Wojciak, A. S., \& Russell, S. T. (2019). Are sexual minority youth overrepresented in foster care, child welfare, and out-of-home placement? Findings from nationally representative data. Child Abuse Negl, 89, 203-211. doi:10.1016/j.chiabu.2019.01.005

Fisher, P. A., \& Kim, H. K. (2007). Intervention effects on foster preschoolers' attachment-related behaviors from a randomized trial. Prevention Science, 8(2), 161-170. doi:10.1007/s11121-0070066-5

Ford, T., Vostanis, P., Meltzer, H., \& Goodman, R. (2007). Psychiatric disorder among British children looked after by local authorities: Comparison with children living in private households. British Journal of Psychiatry, 190(APR.), 319-325. doi:10.1192/bjp.bp.106.025023 
Forsman, H., Brännström, L., Vinnerljung, B., \& Hjern, A. (2016). Does poor school performance cause later psychosocial problems among children in foster care? Evidence from national longitudinal registry data. Child Abuse and Neglect, 57, 61-71. doi:10.1016/j.chiabu.2016.06.006

Forsman, H., \& Vinnerljung, B. (2012). Interventions aiming to improve school achievements of children in out-of-home care: A scoping review. Children and Youth Services Review, 34(6), 1084-1091. doi:10.1016/j.childyouth.2012.01.037

Franzén, E., Vinnerljung, B., \& Hjern, A. (2008). The Epidemiology of Out-of-Home Care for Children and Youth: A National Cohort Study. The British Journal of Social Work, 38(6), 1043-1059. doi:10.1093/bjsw/bcl380

Fredlund, C., Svedin, C. G., Priebe, G., Jonsson, L., \& Wadsby, M. (2017). Self-reported frequency of sex as self-injury (SASI) in a national study of Swedish adolescents and association to sociodemographic factors, sexual behaviors, abuse and mental health. Child and Adolescent Psychiatry and Mental Health, 11(1), 9. doi:10.1186/s13034-017-0146-7

Fängström, K., Bokström, P., Dahlberg, A., Calam, R., Lucas, S., \& Sarkadi, A. (2016). In My Shoes - Validation of a computer assisted approach for interviewing children. Child Abuse Negl, 58, 160-172. doi:10.1016/j.chiabu.2016.06.022

Galvin, E., O'Donnell, R., Skouteris, H., Halfpenny, N., \& Mousa, A. (2019). Interventions and practice models for improving health and psychosocial outcomes of children and young people in outof-home care: Protocol for a systematic review. BMJ Open, 9(9). doi:10.1136/bmjopen-2019-031362

Garsed, J., \& Davies, M. Improving Participation by Children and young People in Care in Western Australia Government of Western Australia

Gauffin, K., Vinnerljung, B., Fridell, M., Hesse, M., \& Hjern, A. (2013). Childhood socio-economic status, school failure and drug abuse: a Swedish national cohort study. Addiction, 108(8), 1441-1449. doi:10.1111/add.12169

Goemans, A., van Geel, M., van Beem, M., \& Vedder, P. (2016). Developmental Outcomes of Foster Children: A Meta-Analytic Comparison With Children From the General Population and Children at Risk Who Remained at Home. Child Maltreat, 21(3), 198-217. doi:10.1177/1077559516657637

Goodman, R. (1997). The Strengths and Difficulties Questionnaire: a research note. The Journal of Child Psychology and Psychiatry, 38(5), 581-586. doi:10.1111/j.1469-7610.1997.tb01545.x 
Greger, H. K., Myhre, A. K., Lydersen, S., \& Jozefiak, T. (2015). Previous maltreatment and present mental health in a high-risk adolescent population. Child Abuse and Neglect, 45, 122-134. doi:10.1016/j.chiabu.2015.05.003

Griffiths, R. (2012). The Letterbox Club: An account of a postal club to raise the achievement of children aged 7 to 13 in foster care. Children and Youth Services Review, 34(6), 1101-1106. doi:10.1016/j.childyouth.2012.01.039

Haggman-Laitila, A., Salokekkila, P., \& Karki, S. (2019). Young People's Preparedness for Adult Life and Coping After Foster Care: A Systematic Review of Perceptions and Experiences in the Transition Period. Child \& Youth Care Forum, 48(5), 633-661. doi:10.1007/s10566-019-09499-4

Harrison, P., \& Oakland, T. (2008). Adaptive Behavior Assessment System - Second edition [Swedish translation]: Pearson Assessments.

Hattie, J. A. C. (2008). Visible learning : a synthesis of over 800 metaanalyses relating to achievement: Routledge.

Hegelund, E. R., Flensborg-Madsen, T., Dammeyer, J., \& Mortensen, E. L. (2018). Low IQ as a predictor of unsuccessful educational and occupational achievement: A register-based study of 1,098,742 men in Denmark 1968-2016. Intelligence, 71, 46-53. doi:10.1016/j.intell.2018.10.002

Heimer, M., Näsman, E., \& Palme, J. (2018). Vulnerable children's rights to participation, protection, and provision: The process of defining the problem in Swedish child and family welfare. Child and Family Social Work, 23(2), 316-323. doi:10.1111/cfs.12424

Hultkrantz, L., Karpaty, P., \& Vimefall, E. (2017). Education-earnings linkage for assessing societal benefits of interventions for children and youth in Sweden. Psychosocial Intervention, 26(3), 171-179. doi:10.1016/j.psi.2017.06.001

Höjer, I., \& Johansson, H. (2013). School as an opportunity and resilience factor for young people placed in care. European Journal of Social Work, 16(1), 22-36. doi:10.1080/13691457.2012.722984

Höjer, I., \& Sjöblom, Y. (2014). Voices of 65 Young People Leaving Care in Sweden: "There Is So Much I Need to Know!". Australian Social Work, 67(1), 71-87. doi:10.1080/0312407X.2013.863957

Hök, L., \& Sanandaji, N. (2017). Samhällsförlusten av skolmisslyckande och värdet av att rädda fler $i$ varje årskull. Retrieved from https://www.ideerforlivet.se/globalassets/pdf/rapporter/samhallsf orlusten-av-skolmisslyckande.pdf

Jackson, S., \& Cameron, C. (2012). Leaving care: Looking ahead and aiming higher. Children and Youth Services Review, 34(6), 11071114. doi:10.1016/j.childyouth.2012.01.041 
Jacobson, C. (2001). Läskedjor Manual. Stockholm: Hogrefe Psykologiförlaget AB.

Jacobson, C. (2014). LäsKedjor-2. För skolår 1 - år 1 i gymnasiet. Stockholm: Hogrefe Psykologiförlaget AB.

Jeffreys, M. D., Leibowitz, R. Q., Finley, E., \& Arar, N. (2010). Trauma disclosure to health care professionals by veterans: Clinical implications. Military Medicine, 175(10), 719-724. doi:10.7205/MILMED-D-10-00054

Jiang, S., Postovit, L., Cattaneo, A., Binder, E. B., \& Aitchison, K. J. (2019). Epigenetic Modifications in Stress Response Genes Associated With Childhood Trauma. Frontiers in Psychiatry, 10. doi:10.3389/fpsyt.2019.00808

Jonsson, L. S., Priebe, G., Bladh, M., \& Svedin, C. G. (2014). Voluntary sexual exposure online among Swedish youth - Social background, Internet behavior and psychosocial health. Computers in Human Behavior, 30, 181-189. doi:10.1016/j.chb.2013.08.005

Jozefiak, T., Kayed, N. S., Rimehaug, T., Wormdal, A. K., Brubakk, A. M., \& Wichstrøm, L. (2016). Prevalence and comorbidity of mental disorders among adolescents living in residential youth care. European Child and Adolescent Psychiatry, 25(1), 33-47. doi:10.1007/s00787-015-0700-x

Järpsten, B., \& Taube, K. (2002). DLS handledning för klasserna 4-6; DLS handledning för klasserna 2-3; DLS handledning för klasserna 46; DLS handledning för skolår 7-9 och år 1 i gymnasiet. Stockholm: Hogrefe Psykologiförlaget AB.

Kaariala, A., Berlin, M., Lausten, M., Hiilamoa, H., \& Ristikari, T. (2018). Early school leaving by children in out-of-home care: A comparative study of three Nordic countries. Children and Youth Services Review, 93, 186-195. doi:10.1016/j.childyouth.2018.06.007

Kim, H. K., \& Leve, L. D. (2011). Substance use and delinquency among middle school girls in foster care: a three-year follow-up of a randomized controlled trial. J Consult Clin Psychol, 79(6), 740750. doi:10.1037/a0025949

Kling, S., Vinnerljung, B., \& Hjern, A. (2016). Somatic assessments of 120 Swedish children taken into care reveal large unmet health and dental care needs. Acta Paediatrica, International Journal of Paediatrics. doi:10.1111/apa.13304

Kungl, M. T., Bovenschen, I., \& Spangler, G. (2017). Early Adverse Caregiving Experiences and Preschoolers' Current Attachment Affect Brain Responses during Facial Familiarity Processing: An ERP Study. Front Psychol, 8(2047), 2047. doi:10.3389/fpsyg.2017.02047 
Köhler, M., Emmelin, M., Hjern, A., \& Rosvall, M. (2015). Children in family foster care have greater health risks and less involvement in Child Health Services. Acta Paediatr, 104(5), 508-513. doi:10.1111/apa.12901

Larsson, I., Staland-Nyman, C., Svedberg, P., Nygren, J. M., \& Carlsson, I.-M. (2018). Children and young people's participation in developing interventions in health and well-being: a scoping review. BMC Health Services Research, 18(1), 507. doi:10.1186/s12913-018-3219-2

Laurens, K. R., Islam, F., Kariuki, M., Harris, F., Chilvers, M., Butler, M., . . . Green, M. J. (2020). Reading and numeracy attainment of children reported to child protection services: A population record linkage study controlling for other adversities. Child Abuse and Neglect, 101. doi:10.1016/j.chiabu.2019.104326

Lehmann, S., Breivik, K., Heiervang, E. R., Havik, T., \& Havik, O. E. (2016). Reactive Attachment Disorder and Disinhibited Social Engagement Disorder in School-Aged Foster Children - A Confirmatory Approach to Dimensional Measures. Journal of Abnormal Child Psychology, 44(3), 445-457. doi:10.1007/s10802015-0045-4

Lehmann, S., Havik, O. E., Havik, T., \& Heiervang, E. R. (2013). Mental disorders in foster children: A study of prevalence, comorbidity and risk factors. Child and Adolescent Psychiatry and Mental Health, 7(1). doi:10.1186/1753-2000-7-39

Leve, L. D., Harold, G. T., Chamberlain, P., Landsverk, J. A., Fisher, P. A., \& Vostanis, P. (2012). Practitioner review: Children in foster care--vulnerabilities and evidence-based interventions that promote resilience processes. J Child Psychol Psychiatry, 53(12), 1197-1211. doi:10.1111/j.1469-7610.2012.02594.x

Liabo, K., Gray, K., \& Mulcahy, D. (2013). A systematic review of interventions to support looked-after children in school. Child \& Family Social Work, 18(3), 341-353. doi:10.1111/j.13652206.2012.00850.x

Lightfoot, E., Hill, K., \& LaLiberte, T. (2011). Prevalence of children with disabilities in the child welfare system and out of home placement: An examination of administrative records. Children and Youth Services Review, $33(11)$, 2069-2075. doi:http://dx.doi.org/10.1016/j.childyouth.2011.02.019

Luke, N., \& O'Higgins, A. (2018). Is the Care System to Blame for the Poor Educational Outcomes of Children Looked After? Evidence from a Systematic Review and National Database Analysis. Children Australia, 43(2), 135-151. doi:10.1017/cha.2018.22 
Mensah, T., Hjern, A., Håkanson, K., Johansson, P., Jonsson, A. K., Mattsson, T., . . Klingberg, G. (2020). Organisational models of health services for children and adolescents in out-of-home care: Health technology assessment. Acta Paediatrica, International Journal of Paediatrics, 109(2), 250-257. doi:10.1111/apa.15002

Miller, L. R., \& Grollman, E. A. (2015). The Social Costs of Gender Nonconformity for Transgender Adults: Implications for Discrimination and Health. Sociological Forum, 30(3), 809-831. doi:10.1111/socf.12193

Mitchell, K. J., Finkelhor, D., \& Wolak, J. (2003). Victimization of youths on the internet. Journal of Aggression, Maltreatment and Trauma, 8(1-2), 1-39. doi:10.1300/J146v08n01_01

Morgan, A., \& Fraser, S. (2009). Looked After Young People and their Social Work Managers: A Study of Contrasting Experiences of Using Computer-Assisted-Self-Interviewing (A-CASI). The British Journal of Social Work, 40(2), 445-461. doi:10.1093/bjsw/bcp009

Mustanski, B., \& Liu, R. T. (2013). A longitudinal study of predictors of suicide attempts among lesbian, gay, bisexual, and transgender youth. Archives of Sexual Behavior, 42(3), 437-448. doi:10.1007/s10508-012-0013-9

National Board of Health and Welfare. (2010). Social report 2010. Retrieved from Stockholm, Socialstyrelsen: https://www.socialstyrelsen.se/Lists/Artikelkatalog/Attachments/ 17957/2010-3-11.pdf

National Board of Health and Welfare. (2016). Individ- och familjeomsorg Lägesrapport 2016. Retrieved from http://www.socialstyrelsen.se/publikationer2016/2016-2-22

National Board of Health and Welfare. (2018). Open comparisons 2018 education and health in out-of-home placements [Press release]. Retrieved from http://www.socialstyrelsen.se/Lists/Artikelkatalog/Attachments/2 0887/2018-3-12.pdf

National Board of Health and Welfare. (2019a). Individ- och Familjeomsorg, Lägesrapport 2019. Retrieved from https://www.socialstyrelsen.se/globalassets/sharepointdokument/artikelkatalog/ovrigt/2019-3-19.pdf

National Board of Health and Welfare. (2019b). Statistics on social welfare to children and young persons 2018. Retrieved from https://www.socialstyrelsen.se/globalassets/sharepointdokument/artikelkatalog/statistik/2019-8-6261-tabeller.xls

Neil, A. L., Islam, F., Kariuki, M., Laurens, K. R., Katz, I., Harris, F., . . . Green, M. J. (2020). Costs for physical and mental health 
hospitalizations in the first 13 years of life among children engaged with Child Protection Services. Child Abuse Negl, 99, 104280. doi:10.1016/j.chiabu.2019.104280

Nilsson, I. (2012). Sociala investeringar kring barn och unga. Retrieved from

https://www.ideerforlivet.se/globalassets/pdf/rapporter/130301soc inv 1301.pdf

Okpych, N. J., \& Courtney, M. E. (2014). Does education pay for youth formerly in foster care? Comparison of employment outcomes with a national sample. Children and Youth Services Review, 43, 18-28. doi:10.1016/j.childyouth.2014.04.013

Oriana Linares, L., Montalto, D., Li, M., \& Oza, V. S. (2006). A promising parenting intervention in foster care. Journal of Consulting and Clinical Psychology, 74(1), 32-41. doi:10.1037/0022006X.74.1.32

Pecora, P. J., Kessler, R. C., O'Brien, K., White, C. R., Williams, J., Hiripi, E., . . . Herrick, M. A. (2006). Educational and employment outcomes of adults formerly placed in foster care: Results from the Northwest Foster Care Alumni Study. Children and Youth Services Review, 28(12), 1459-1481. doi:10.1016/j.childyouth.2006.04.003

Plöderl, M., \& Tremblay, P. (2015). Mental health of sexual minorities. A systematic review. International Review of Psychiatry, 27(5), 367385. doi:10.3109/09540261.2015.1083949

Poulton, L., \& National Literacy, T. (2012). Looked-After Children and Literacy: A Brief Review. Retrieved from http://search.ebscohost.com/login.aspx?direct=true \&db=eric\&A $\mathrm{N}=\mathrm{ED} 541601 \&$ site $=$ ehost-live

Priebe, G., \& Svedin, C. G. (2009). Prevalence, characteristics, and associations of sexual abuse with sociodemographics and consensual sex in a population-based sample of Swedish adolescents. Journal of Child Sexual Abuse, 18(1), 19-39. doi:10.1080/10538710802584635

Priebe, G., \& Svedin, C. G. (2012). Online or off-line victimisation and psychological well-being: A comparison of sexual-minority and heterosexual youth. European Child and Adolescent Psychiatry, 21(10), 569-582. doi:10.1007/s00787-012-0294-5

Pösö, T., Skivenes, M., \& Hestbæk, A. D. (2014). Child protection systems within the Danish, Finnish and Norwegian welfare states-time for a child centric approach? European Journal of Social Work, 17(4), 475-490. doi:10.1080/13691457.2013.829802 
Randsalu, L. S., \& Laurell, L. (2018). Children in out-of-home care are at high risk of somatic, dental and mental ill health. Acta Paediatr, 107(2), 301-306. doi:10.1111/apa.14108

Rosenberg, M. (2015). Society and the Adolescent Self Esteem: Princeton University Press.

Rosenthal, M. K. (1999). Out-of-home child care research: A cultural perspective. International Journal of Behavioral Development, 23(2), 477-518. doi:10.1080/016502599383928

Sallnäs, M., Wiklund, S., \& Lagerlöf, H. (2012). Welfare resources among children in care. European Journal of Social Work, 15(4), 467483. doi:10.1080/13691457.2012.702313

Schino, G., \& Aureli, F. (2010). The relative roles of kinship and reciprocity in explaining primate altruism. Ecol Lett, 13(1), 45-50. doi:10.1111/j.1461-0248.2009.01396.x

Sebba, J., \& Luke, N. (2019). The educational progress and outcomes of children in care: editorial. Oxford Review of Education, 45(4), 435-442. doi:10.1080/03054985.2019.1622281

Sinclair, I., Luke, N., \& Berridge, D. (2019). Children in care or in need: educational progress at home and in care. Oxford Review of Education, 45(4), 443-460. doi:10.1080/03054985.2019.1600488

Skandia. (2019). Hälsa och trygghet för barn och unga. Retrieved from https://www.ideerforlivet.se/globalassets/pdf/rapporter/ideerforli vet-halsa-och-trygghet-for-barn-och-unga.2019.pdf

Smedje, H., Broman, J.-E., Hetta, J., \& von Knorring, A.-L. (1999). Psychometric properties of a Swedish version of the "Strengths and Difficulties Questionnaire". European Child \& Adolescent Psychiatry, 8(2), 63-70. doi:10.1007/s007870050086

Statistics Sweden. (2019a). Population by age and sex. Year 1860 - 2018. Retrieved from http://www.statistikdatabasen.scb.se/pxweb/en/ssd/START BE BE0101 BE0101A/BefolkningR1860/

Statistics Sweden. (2019b). Unaccompanied refugee minors by age, citizenship, sex. Year 2002 - 2018. Retrieved from http://www.statistikdatabasen.scb.se/pxweb/en/ssd/START BE BE0101 BE0101P/Ensamkommande/

Svedin, C. G., \& Priebe, G. (2007). Selling sex in a population-based study of high school seniors in Sweden: Demographic and psychosocial correlates. Archives of Sexual Behavior, 36(1), 21-32. doi:10.1007/s10508-006-9083-x

Svedin, C. G., Priebe, G., Wadsby, M., Jonsson, L., \& Fredlund, C. (2015). Unga sex och Internet - $i$ en föränderlig värld (9789176855379 (ISBN)). Retrieved from Linköping: http://urn.kb.se/resolve?urn=urn:nbn:se:liu:diva-125885 
Tideman, E., Vinnerljung, B., Hintze, K., \& Aldenius Isaksson, A. (2011). Improving Foster Children's School Achievements: Promising Results from a Swedish Intensive Study. Adoption \& Fostering, 35(1), 44-56. doi:10.1177/030857591103500106

Toomey, R. B., Ryan, C., Diaz, R. M., Card, N. A., \& Russell, S. T. (2010). Gender-nonconforming lesbian, gay, bisexual, and transgender youth: school victimization and young adult psychosocial adjustment. Dev Psychol, 46(6), 1580-1589. doi:10.1037/a0020705

Tordön, R., Vinnerljung, B., \& Axelsson, U. (2014). Improving foster children's school performance: a replication of the Helsingborg study. Adoption \& Fostering, 38(1), 37-48. doi:10.1177/0308575913518003

Turney, K., \& Wildeman, C. (2017). Adverse childhood experiences among children placed in and adopted from foster care: Evidence from a nationally representative survey. Child Abuse Negl, 64, 117-129. doi:10.1016/j.chiabu.2016.12.009

Upadhyaya, S., Chudal, R., Luntamo, T., Sinkkonen, J., Hinkka-YliSalomäki, S., Kaneko, H., \& Sourander, A. (2019). Parental Risk Factors among Children with Reactive Attachment Disorder Referred to Specialized Services: A Nationwide Population-Based Study. Child Psychiatry Hum Dev, 50(4), 546-556. doi:10.1007/s10578-018-00861-6

Wade, R., Jr., Cronholm, P. F., Fein, J. A., Forke, C. M., Davis, M. B., Harkins-Schwarz, M., . . . Bair-Merritt, M. H. (2016). Household and community-level Adverse Childhood Experiences and adult health outcomes in a diverse urban population. Child Abuse Negl, 52, 135-145. doi:10.1016/j.chiabu.2015.11.021

Ward, J., \& Smeeton, J. (2017). The End of Non-Consensual Adoption? Promoting the Wellbeing of Children in Care. Practice, 29(1), 5573. doi:10.1080/09503153.2016.1164131

Vasileva, M., \& Petermann, F. (2017). Mental health needs and therapeutic service utilization of young children in foster care in Germany. Children and Youth Services Review, 75, 69-76. doi:10.1016/j.childyouth.2017.02.022

Wechsler, D. (1991). Manual for the Wechsler Intelligence Scale for Children-WISC III.

Wechsler, D. (2003). Wechsler intelligence scale for children - fourth edition (Swedish translation ed.): NCS Pearson, Inc.

Westermark, P. K., Hansson, K., \& Olsson, M. (2011). Multidimensional treatment foster care (MTFC): Results from an independent replication. Journal of Family Therapy, 33(1), 20-41. doi:10.1111/j.1467-6427.2010.00515.x 
Wilson, B., \& Barnett, L. M. (2020). Physical activity interventions to improve the health of children and adolescents in out of home care - A systematic review of the literature. Children and Youth Services Review, 110. doi:10.1016/j.childyouth.2020.104765

Wilson, B. D. M., Jordan, S. P., Meyer, I. H., Flores, A. R., Stemple, L., \& Herman, J. L. (2017). Disproportionality and Disparities among Sexual Minority Youth in Custody. J Youth Adolesc, 46(7), 15471561. doi:10.1007/s10964-017-0632-5

Wilson, B. D. M., \& Kastanis, A. A. (2015). Sexual and gender minority disproportionality and disparities in child welfare: A populationbased study. Children and Youth Services Review, 58, 11-17. doi:10.1016/j.childyouth.2015.08.016

Vinnerljung, B. (2012). Suicide and attempted suicide are more common in children and adolescents in care, but rates of attempted suicide are higher before entry into care than after. Evidence-Based Mental Health, 15(2), 38. doi:10.1136/ebmental-2011-100526

Vinnerljung, B., \& Hjern, A. (2011). Cognitive, educational and selfsupport outcomes of long-term foster care versus adoption. A Swedish national cohort study. Children and Youth Services Review, 33(10), 1902-1910. doi:10.1016/j.childyouth.2011.05.016

Vinnerljung, B., \& Sallnäs, M. (2008). Into adulthood: A follow-up study of 718 young people who were placed in out-of-home care during their teens. Child and Family Social Work, 13(2), 144-155. doi:10.1111/j.1365-2206.2007.00527.x

Vinnerljung, B., Öman, M., \& Gunnarson, T. (2005). Educational attainments of former child welfare clients - A Swedish national cohort study. International Journal of Social Welfare, 14(4), 265276. doi:10.1111/j.1369-6866.2005.00369.x

Winter, K. (2012). Understanding and Supporting Young Children's Transitions into State Care: Schlossberg's Transition Framework and Child-Centred Practice. The British Journal of Social Work, 44(2), 401-417. doi:10.1093/bjsw/bcs128

World Health Organization. Retrieved from http://www.emro.who.int/about-who/public-healthfunctions/health-promotion-disease-prevention.html

World Medical Association. (2013). World Medical Association Declaration of Helsinki: Ethical Principles for Medical Research Involving Human Subjects. JAMA, 310(20), 2191-2194. doi:10.1001/jama.2013.281053

Yeater, E., Miller, G., Rinehart, J., \& Nason, E. (2012). Trauma and Sex Surveys Meet Minimal Risk Standards: Implications for Institutional Review Boards. Psychological Science, 23(7), 780787. doi:10.1177/0956797611435131 


\section{Papers}

The papers associated with this thesis have been removed for copyright reasons. For more details about these see:

http://urn.kb.se/resolve?urn=urn:nbn:se:liu:diva-165555 


\section{FACULTY OF MEDICINE AND HEALTH SCIENCES}

Linköping University Medical Dissertation No. 1739, 2020

Department of biomedical and clinical sciences

Linköping University

SE-581 83 Linköping, Sweden

www.liu.se 